\title{
Seeing the Forest for the Trees: The Limitations of Phylogenies in Comparative Biology
}

\section{Citation}

Losos, Jonathan B. 2011. Seeing the forest for the trees: The limitations of phylogenies in comparative biology. American Naturalist 177(6): 709-727.

\section{Published Version}

doi:10.1086/660020

\section{Permanent link}

http://nrs.harvard.edu/urn-3:HUL.InstRepos:9751933

\section{Terms of Use}

This article was downloaded from Harvard University's DASH repository, and is made available under the terms and conditions applicable to Open Access Policy Articles, as set forth at http:// nrs.harvard.edu/urn-3:HUL.InstRepos:dash.current.terms-of-use\#OAP

\section{Share Your Story}

The Harvard community has made this article openly available.

Please share how this access benefits you. Submit a story.

Accessibility 
Seeing the Forest for the Trees:

The Limitations of Phylogenies in Comparative Biology

Jonathan B. Losos

Museum of Comparative Zoology and Department of Organismic and Evolutionary Biology

Harvard University

26 Oxford St.

Cambridge, MA 02138 


\begin{abstract}
$\underline{\text { Abstract }}$
The last 30 years have seen a revolution in comparative biology. Prior to that time, systematics was not at the forefront of the biological sciences, and few scientists considered phylogenetic relationships when investigating evolutionary questions. By contrast, systematic biology is now one of the most vigorous disciplines in biology, and the use of phylogenies is not only requisite in macroevolutionary studies, but has been applied to a wide range of topics and fields that no one could possibly have envisioned 30 years ago. My message is simple: phylogenies are fundamental to comparative biology, but they are not the be all and end all. Phylogenies are powerful tools for understanding the past, but like any tool, they have their limitations. In addition, phylogenies are much more informative about pattern than they are about process. The best way to fully understand the past - both pattern and process - is to integrate phylogenies with other types of historical data as well as with direct studies of evolutionary process.
\end{abstract}


I start with two observations about evolutionary biology. First, as attendance at the 2010 joint meeting of the American Society of Naturalists, the Society for the Study of Evolution, and the Society of Systematic Biologists attests, evolutionary biology is a thriving science. One sign of the health of this science, evident to any participant at the meeting, is the number of young people entering the field. This leads to my second observation. Evolutionary biology is inherently about history, the progression of life through time.

Given these two points, I begin my essay by providing a service to the younger members of the field. In my ASN Presidential Address (from which this essay is adapted), I asked all members of the audience born since 1980 to raise their hands. My estimate, looking out upon the assembled masses, was that approximately $61.31 \%$ of the audience (was in this fledgling class. ${ }^{1}$ These young workers, then, do not personally know the field of evolutionary biology before the year 2000 or so, much less what it was like in the 1970's, before their birth. So, in the spirit of a historical science, I briefly review what life was like in that ancient time.

\section{A Short History of Modern Comparative Approaches}

Ahh, the 1970's: bell bottoms and big hair. Disco, Abba and Led Zep. Happy Days, Grease, and Star Wars. Tricky Dick and Watergate. Not to mention the Oil Embargo (the result of a time when we relied on oil imported from the Middle East for much of our energy).

But what about evolutionary biology? In particular, the more historical, systematic, macroevolutionary side of the field, which is so vibrant today. What was it like? In a word, it was non-existent. The importance of a historical, evolutionary perspective was realized, at least by some (e.g., Mayr, 1976), but systematics itself was a scientific backwater. The construction of phylogenies often was more an art than a science; evolutionary trees were constructed using simplistic algorithms or none at all. The use of phylogenies to investigate evolutionary questions was almost unheard of. ${ }^{2}$

How did we get from there to today, where the use of phylogenies is de rigueur in comparative analyses and where new methods, each more sophisticated and complex than the last, are published on an almost daily basis? Comparative biologists of the 1980's had the good fortune to actually observe, as it happened, something akin to a Kuhnian paradigm shift as the old approach to studying comparative biology and evolutionary change was supplanted by a completely different perspective.

It all started with phenetics, which attempted to provide a rigorous, quantitative and statistical basis for taxonomy. Phenetics, in turn, was supplanted by cladistics, which aimed to infer evolutionary relationships and had the insight to separate ancestral versus derived similarity. ${ }^{3}$ Concomitant with the rise of cladistics, researchers increasingly recognized the

\footnotetext{
${ }^{1}$ Of the 1,950 people registered for the meeting in Portland, 47\% were students (including 134 undergraduates!) and $19 \%$ were postdocs.

${ }^{2}$ I need to credit my mentors. Ernest Williams, my undergraduate advisor, was well ahead of his time, and his 1972 Evolutionary Biology paper utilized a phylogenetic tree to infer patterns of character evolution in ways conceptually identical to what we do today, presaging by nearly 20 years the rise of comparative phylogenetic biology. Similarly, my doctoral advisor, Harry Greene, in his own dissertation work, was far ahead of the field in using a comparative phylogenetic perspective to understand the evolution of behavior (Greene and Burghardt, 1978).

${ }^{3}$ Hull (1988) provides an authoritative and captivating history of the rise of phylogenetic systematics.
} 
historical component of evolutionary biology, realizing that macroevolutionary patterns should only be examined in an explicitly phylogenetic context.

Such "tree thinking" (O'Hara, 1988) began in the field of historical biogeography (Rosen, 1978; Platnick and Nelson, 1978) and was increasingly espoused by the early 1980's (e.g., Cracraft, 1981; Gittleman, 1981; Lauder, 1981; Ridley, 1983; Clutton-Brock and Harvey, 1984; Brooks, 1985), but the key turning point was the publication of Felsenstein's (1985) paper in the American Naturalist presenting the issue of shared ancestry as a difficulty in comparative analysis and the independent contrasts method as the solution. ${ }^{4}$ Followed by a paper by Huey and Bennett (1987) proposing another method, evolutionary biologists had the analytical means to incorporate phylogenies into comparative analyses. After a short lull, ${ }^{5}$ the publication of books by Brooks and McLennan (1991) and Harvey and Pagel (1991) completed the revolution. Since that time, there has been a continuous, unabated rise in the development and use of phylogenetic comparative methods. Comparative studies now are essentially unpublishable unless analyzed in a phylogenetic context, and phylogenies are now employed to investigate a wide variety of questions far beyond what anyone would have imagined a mere twenty years ago (e.g., to study community composition and abundance, to detect the workings of natural selection and to conduct meta-analyses).

\section{Why Phylogeny Matters}

Before proceeding, I will quickly review the basis for the argument that phylogenetic information must be included in comparative studies. As a generality, phylogenies are important in two main respects in comparative analyses, for appropriate statistical analysis and for inferring ancestral phenotypes and past evolutionary conditions and events. With regard to statistics, Harvey and Pagel (1991, p.35) put it well when they said, "Phylogenies help us to identify independent evolutionary events, and it is independent events that statistical tests rely on." Felsenstein (1985) identified this clearly by showing that if closely related species tend to be phenotypically similar, a phenomenon known as "phylogenetic effect" (Derrickson and Ricklefs, 1988), then two traits may covary among species, even if the traits do not evolve in a correlated manner (Figure 1). Put another way, ordinary statistical methods assume independence of data, but this may not be the case for evolutionarily related species. Phylogenetic comparative methods incorporate the non-independence due to phylogeny directly in the error structure when assessing patterns, which allows such non-independence to be accounted for statistically. Phylogenies also may be used to reconstruct ancestral phenotypes and the pattern of evolutionary change, and are used to infer changes in diversity, such as the rate at which the species richness of a clade has changed through time.

Phylogenetic effects could arise for a number of reasons. Most simply, if evolutionary change occurs in a Brownian motion (BM) manner in which change is small and non-directional from one generation to the next, as might arise from genetic drift or fluctuating natural selection, then phenotypic similarity will be a function of phylogenetic relatedness - the more recently two

\footnotetext{
${ }^{4}$ In February, 2011, this paper has been cited 3,854 times according to Google Scholar.

${ }^{5}$ My 1990 Ecological Monographs paper was, to my knowledge, the second to employ the independent contrasts method (after Sessions and Larson, 1987) and the first, after the original, to use the Huey and Bennett squaredchange parsimony method. I point this out not only to demonstrate that there was a delay before these methods were widely adopted, but also to establish my bona fides as someone who has been involved in using phylogenetic comparative methods from the approach's inception.
} 
taxa shared a common ancestor, the more likely that they will be similar in phenotype (Figure 2). Any factor that constrains evolutionary change and that is shared among related species can also produce phylogenetic effect. For example, if related species experience similar stabilizing selection pressures, then they will tend to be phenotypically similar. If all species within a clade experience the same selection, of course, then given enough time there will be no phylogenetic effect as historical effects will be erased by the pull of selection back toward the same selective optimum, as discussed below. However, if occasional shifts in selective regime occur throughout a clade's history, then the existence of different selective optima in different clades will lead to phylogenetic effect (Figure 3). The same reasoning holds for phylogenetically inherited constraints on the production of phenotypic variation (e.g., developmental, genetic, or architectural constraints); as long as the constraints themselves evolve, but at a relatively low rate such that closely related species tend to share the same constraint, then closely related species will be phenotypically similar.

\section{The Swinging Pendulum}

Felsenstein argued (1985, p.14) that "phylogenies are fundamental to comparative biology. There is no doing it without taking them into account." Within a few years, this viewpoint swept through the systematic and evolutionary biology communities. Dobzhansky's famous quote has frequently been reworked to "nothing in biology makes sense except in the light of phylogeny" (MacLeod, 2001, p.237; see also, e.g., Grandcolas et al., 1997; Johnson, 2003; Society of Systematic Biology website, 2010). Whereas a phylogenetic perspective on evolution was nearly entirely absent prior to the 1980's, it is now ubiquitous. Phylogenetic analyses are now an integral part of the comparative biologist's toolkit and one often gets the sense that many comparative biologists believe that a phylogeny is not only necessary, but also sufficient, to answer any evolutionary question.

My point here is to argue simply that the pendulum has swung too far. Phylogenies are, indeed, fundamental to evolutionary analysis. Nonetheless, the phylogenetic perspective is not all powerful; by themselves, phylogenies cannot entirely answer many questions, and in some cases, phylogenies provide relatively little insight into the workings and history of evolutionary change. In particular, I will argue that:

1. Many traits in many clades do not exhibit phylogenetic effect;

2. Our ability to reconstruct particular past events is limited;

3. Phylogenetic approaches are not suitable for traits that evolve frequently and substantially within species; and

4. Phylogenies depict patterns, not processes.

Before addressing these points, I need to explicitly make clear that I am not arguing that phylogenies are unimportant, nor that we should stop working on them. Quite the contrary, phylogenies truly are essential to comparative biology. Indeed, in many of the cases I will discuss below, we could not determine that a phylogenetic perspective is not sufficient to address particular questions if we didn't have the phylogeny in hand in the first place. My goal here is not to argue against the utility of phylogenetics, but to recognize that phylogenetics is only one 
of the tools available to comparative biologists; like any tool, the phylogenetic approach is good at addressing some questions, but less successful in addressing others (Systma and Pires, 2001). ${ }^{6}$

\section{Many Traits in Many Clades Do Not Exhibit Phylogenetic Effect}

Two surveys from nearly a decade ago differed in the extent to which phylogenetic effect-i.e., that is, a relationship between degree of phylogenetic relatedness and degree of phenotypic similarity - was found in different taxa and types of characters (Freckleton et al., 2002; Blomberg et al., 2003). Regardless of its exact frequency, lack of phylogenetic effect is widely reported in the literature (Box 1). Given the explosion of phylogenetic analyses in the last decade, a good meta-analysis of how commonly little or no phylogenetic effect is found in comparative studies, and how this differs among types of traits and different contexts, could prove interesting. In the meantime, however, what is clear is that a wide range of traits across a diverse range of taxa fail to exhibit substantial phylogenetic effects.

How can the seemingly high incidence of lack of phylogenetic effect be reconciled with the many reasons listed above about why phylogenetic effect might be expected? The answer is that there are just as many scenarios in which phylogenetic effect would not occur. For example, if phenotypic space is bounded, then independently evolving lineages are likely by chance to end up in the same place in phenotypic space (Revell et al., 2008); such convergent evolution (a.k.a., homoplasy) is the antithesis of phylogenetic effect. This is analogous to what is clearly seen in evolution of DNA, where the limitation imposed by the existence of only four nucleotides produces the famously high levels of homoplasy in DNA data. Above, I pointed out that stabilizing selection could produce phylogenetic effect, but that assumed that occasional evolutionary shifts occurred such that closely related species tended to share selective regimes. However, if all clades experience the same selective conditions, then phenotypic similarity would not be a function of phylogenetic relatedness. Populations that deviated from the selective optimum would be pulled back by selection, and there would be no long-lasting imprint of history. Clades in which all members share the same evolutionary constraint that prevented evolutionary divergence would similarly lack phylogenetic effect. Conversely, if selective regimes and constraints change independently and frequently relative to the pace of speciation, closely related species again would not tend to be similar, this time because the high rate of change in selection or constraint would lead to divergence even among closely related species. In many cases, particularly those traits studied by evolutionary ecologists, these conditions - in which rates of evolutionary change are high and convergence common-may hold, and thus the lack of phylogenetic effect might be expected.

Lack of phylogenetic effect has two important consequences for comparative biologists. First, as Harvey and Pagel so eloquently put it (above), the need to incorporate phylogenetic information into comparative analyses stems from the observation that phenotypic values of closely related species are not statistically independent. Lack of phylogenetic effect suggests that phenotypic values for closely related species for the trait in question are, indeed,

\footnotetext{
${ }^{6}$ This paragraph has been present in all earlier versions of this manuscript. Nonetheless, many readers of this paper (see acknowledgements), especially those with a systematic bent, have been concerned that it will give license to ecologists and other ne'er-do-wells to ignore phylogenetic approaches entirely. So, just to be clear, I will say it again: phylogenetics is an important approach for studying historical events, and only by explicitly incorporating phylogenetic information can one deduce that, in a particular case, such information provides limited insight. This paper should not be read as license to ignore phylogenetic information in evolutionary studies!
} 
independent, raising the possibility that incorporating phylogenetic information into statistical analyses may be unnecessary or even inappropriate (e.g., Bjørklund, 1997; Losos, 1999, but see discussion below on non-Brownian motion models of character evolution). Workers in this area point out that phylogenetic comparative methods are increasingly sophisticated (e.g., Freckleton et al., 2002; Blomberg et al., 2003), and that lack of phylogenetic effect is one end of a continuum, posing no problem for the use of these methods (e.g., Blomberg et al., 2003; Revell, 2010). On the other hand, these methods require many assumptions that often may be difficult to test in a statistically powerful way, such as the constancy of rates of evolution among clades and through time, and the appropriateness of particular models of character evolution (see, e.g., Blomberg et al., 2003; Butler and King, 2004; Revell, 2010). In the real world of empirical analysis, when phylogenetic effect is weak, it may be unclear how the potential error introduced due to inaccuracy in the parameter estimates of these methods compares to the error resulting from ignoring phylogenetic information. This topic has been little explored and would seem to be a worthwhile area for future work.

The second consequence of the frequent lack of phylogenetic effect is that researchers should not assume a priori that phylogenetic effect exists. ${ }^{7}$ In many studies, the existence of phylogenetic effect is implicitly assumed. For example, in the increasingly popular area of community phylogenetics (e.g., Webb, 2000; Cavender-Bares et al., 2004; Kraft et al., 2007; Cooper et al., 2008; reviewed in Cavender-Bares et al., 2009; Vamosi et al., 2009), many researchers interpret patterns under the assumption that closely related species are ecologically similar. In such studies, if members of a community are more closely related phylogenetically than might be expected by chance, many researchers automatically assume that, because closely related species are phenotypically similar, habitat filtering must have occurred, in which only species with appropriate adaptations can occur in a given habitat. Of course, an alternative explanation is that closely related species have diverged ecologically as a result of competitive pressures, and thus co-occur as a result of their evolved niche partitioning. Thus, the pattern of co-occurrence of closely-related species could be explained in two very different ways depending on whether closely related species are ecologically similar or not-phylogenetic effect should be measured directly, rather than assumed from the outset (see reviews in Cavender-Bares et al., 2009; Vamosi et al., 2009).

\section{Our Ability to Reconstruct Particular Past Events Is Limited}

Since the time of Darwin, one of the primary goals of evolutionary biology has been to understand the historical progression of life through time. The fossil record provides such information, and we have an ever-increasing number of case studies documenting the evolutionary history of particular groups. Nonetheless, the fossil record is notoriously imperfect, and for many groups and key evolutionary transitions, the fossil record does not tell us what happened.

This was, and continues to be, one of the primary appeals of phylogenetic data; by examining the distribution of character states among species in the context of their phylogenetic relationships, we can infer the phenotypic state of ancestral species, as well as the pattern of evolutionary change through time, even in the absence of data from fossils. In addition, by examining the topology of a phylogeny, we can infer rates of speciation and extinction, and how they have changed, through time.

\footnotetext{
${ }^{7}$ Nor should they assume that it does not exist. See previous footnote.
} 


\section{Ancestor Reconstruction}

Phylogenies have been widely used to reconstruct ancestral character states. For example, I reconstructed the evolution of habitat specialists (termed "ecomorphs") in two island radiations of Anolis lizards, inferring that the habitat specialists not only had evolved in almost the same order on both islands, but also that early in the radiation, ancestral species on both islands had nearly identical "generalist" morphologies (Figure 4; Losos, 1992). More recently, phylogenetic methods have been used to infer all manner of ancestral character states, such as the visual pigment of the ancestral archosaur (Chang et al., 2002) and the genome size of dinosaurs (Organ et al., 2007), as well as reconstructing the evolution of spectral sensitivity in vertebrate opsins and receptor sensitivity in steroid hormones (Dean and Thornton, 2007; Liberles, 2007).

Unfortunately, even as it has become increasingly popular, we have come to realize that the process of reconstructing ancestral character states is fraught with problems and that in many cases, ancestral character states cannot be reconstructed with high levels of confidence. The problem is that many traits, particularly those of interest to evolutionary ecologists, evolve rapidly relative to the rate of speciation, and with considerable amounts of convergence. At its essence, accurate and precise ancestor reconstruction relies on assumptions of the opposite. If traits change relatively rarely, and with little homoplasy, then closely related species will tend to be similar, inheriting the same character state from their shared ancestor, and reconstructions of ancestral states are likely to be correct. But when these assumptions do not hold, reconstructions usually will be ambiguous or poorly supported (a problem first highlighted in the context of phylogenetic comparative methods by Frumhoff and Reeve [1994] in a paper whose point I did not sufficiently appreciate when it first appeared [Larson and Losos, 1995]).

A simple example illustrates the problem. Looking again at the anole habitat specialist types (of which there are six) across the four islands of the Greater Antilles, a simple parsimonybased reconstruction of ancestral types reveals that 17 evolutionary changes occurred from one type to another and that the "trunk-ground" habitat specialist evolved relatively late in the radiation (Figure 5a). However, if we instead insist that the trunk-ground state was ancestral for the radiation, only 18 transitions are required (Figure 5b). Obviously, if habitat specialist type has evolved at least 17 times, we can't strongly favor a scenario requiring 18 changes over one requiring 18 , yet the evolutionary scenarios suggested in these two cases differ greatly. ${ }^{8}$

More sophisticated methods to assess confidence in ancestor reconstructions demonstrate this quantitatively (e.g., Schluter et al., 1997; Garland et al. 1999; Rohlf, 2001; Ané, 2008). When all members of a clade share the same character state, then the ancestor is reconstructed with that character state with high confidence (Figure 6). But when many evolutionary transitions have occurred, such that close relatives often differ in character state, then character reconstructions become ambiguous, with multiple possibilities receiving approximately equal support (Figure 7). Thus, we probably should not expect ancestor reconstruction to provide strongly supported inferences of ancestral character states in clades in which there has been extensive evolutionary change and convergence. Unfortunately, these are the clades that generally are of greatest interest to evolutionary ecologists!

If the issue were simply that ancestor reconstructions are often poorly supported, then compulsory reporting of support for reconstructions would make the problem transparent. However, the situation is worse than this because ancestor reconstructions can be positively

\footnotetext{
${ }^{8}$ For more extensive discussion of issues concerning ancestor reconstruction in general, as well as anole evolution in particular, see Losos (2009), chapters 5 and 7.
} 
misleading. Most methods for reconstructing ancestral states for quantitatively varying characters generally assume that character change is unbiased, as likely to evolve in one direction as the other, with the result that inferred ancestral states must lie within the bounds of variation exhibited by the taxa in the study. ${ }^{9}$ However, we also know from the fossil record that trends in evolutionary direction occur commonly (e.g., Vermeij, 1987; McNamara, 1990). Because phylogenetic analyses usually are based only on extant taxa, such trends may be difficult or impossible to detect (Oakley and Cunningham, 2000; Webster and Purvis, 2002; but see Polly, 2001). For example, in a laboratory study in which a phylogeny was created by periodically dividing bacteriophage $\mathrm{T} 7$ colonies, a substantial decrease in the size of plaques on the lawn of $E$. coli occurred independently in all lineages. The result is that none of the lineages produced plaques remotely approaching that of the ancestor, and ancestor reconstruction methods inferred, incorrectly, that the ancestor, too, was quite small (Figure 8; Oakley and Cunningham, 2000). A similar example from the real world was reported recently in a survey across fish families, which reconstructed, for each extant family, the inferred size of the ancestor of that clade and compared that to the size of early fossils assigned to that clade (Albert et al., 2009). In almost all cases, inferred sizes were substantially larger than the fossils, suggesting that trends toward large size had erased the evidence of early ancestral small size, producing inaccurate ancestral reconstructions (Figure 9; see also Finarelli and Flynn, 2006).

Even in the absence of directional evolutionary trends, character evolution may not conform to the Brownian motion assumption that change is equally likely in all directions. For example, stabilizing selection may favor an optimal value for a trait and as a population deviates from this value, selection will increasingly strongly favor change back toward this optimum. This constraining effect could be detected by fitting a significant single-peak Ornstein-Uhlenbeck (OU) model of trait evolution (Felsenstein, 1988; Hansen, 1997; Butler and King, 2004).

The occurrence of such constraints on evolutionary change has several consequences for the reconstruction of ancestral character states. Most obviously, if character evolution occurred in this way, attempts to reconstruct character evolution under a Brownian motion model would fail to produce accurate results. Fortunately, statistical analysis can be used to assess whether an OU model provides a better fit to the data (Butler and King, 2004; Kozak and Wiens, 2010). A more challenging situation arises when occasional niche shifts have occurred, such that species in different parts of a phylogeny have experienced selection drawing them toward different optimal peaks. When such peak shifts can be identified a priori, testing whether a multi-peaked model better describes the data than single-peak OU, BM, or any other model is straightforward (Butler and King, 2004). When no a priori expectation exists, then the analysis of this pattern becomes more problematic because statistically testing peaks identified based on species values has an inherent risk of circularity (but see Revell, in review, for a promising new approach).

The existence of multi-peaked adaptive landscapes also changes the fundamental calculus of phylogenetic effects, which no longer would be manifest as a relationship between phenotypic

\footnotetext{
${ }^{9}$ Methods have been developed to estimate the asymmetry in rates of change in different directions for qualitative characters, such as presence or absence of a character. Goldberg and Igic (2008) provide an insightful analysis of the promise and pitfalls of this approach. One particular difficulty, made evident by Maddison et al. (2007), is that reconstructions of character states take as given the underlying phylogeny, but it is also possible that likelihood of speciation and extinction are a function of character state, which would mean that the phylogeny and ancestral character states would need to be inferred simultaneously, rather than sequentially; failing to so would risk substantial inaccuracy in character reconstruction (Maddison, 2006; Paradis, 2008).
} 
and phylogenetic similarity. In an OU world, phenotypic similarity is a plesiomorphic trait, the result of inheritance of an ancestral species' selective environment or intrinsic constraint. Hence, the expectation from a Brownian motion framework that phenotypic similarity will be a simple linear function of phylogenetic similarity no longer necessarily holds. On one hand, the constraining effect that occurs among species selected toward the same peak means that historical deviations will eventually be erased as species are pulled back toward the optimal value. Conversely, when a species experiences a niche shift to a new selective peak, it would only be transiently phenotypically similar to closely related species in the ancestral niche; eventually species in the ancestral niche would be more phenotypically similar to more distantly related species in their own niche than to their closer relatives in the derived niche.

Of course, stabilizing selection is only one way in which characters can evolve in a non$\mathrm{BM}$ fashion across a phylogeny. Some studies have modeled character evolution as declining in rate through time, as might result, for example, as niches are filled during an adaptive radiation (e.g., Harmon et al., 2010; Mahler et al., 2010). Moreover, in reality, character evolution probably varies more heterogeneously in time and across clades.

This discussion highlights the importance of appropriate models of evolutionary character change. When phylogenetic comparative methods were in their infancy, a frequent criticism (e.g., Carpenter, 1992) was that they were based on a model, Brownian motion, that was known to not provide a good description of evolutionary change. Now we have increasingly sophisticated models that can incorporate different modes of change, different degrees of phylogenetic effect, changes in the rate of evolution through time and variation in a number of other evolutionary parameters. The great success of molecular systematics has resulted from the development of sophisticated models of DNA evolution and the ability to test model parameters to evaluate the fit of the data to the model employed. The theory of phenotypic evolution lags behind that for DNA. As theories of character evolution become incorporated into phylogenetic comparative methods, the ability to tune these methods to observed evolutionary patterns will be ever greater. Of critical importance, however, will be testing whether the assumptions of these methods are met by the data at hand.

More generally, the bottom line is that we should not expect to always be able to confidently reconstruct ancestral character states, even when model assumptions are met. In some situations, we will be able to do so (though such confidence may be misplaced if pervasive biases have led to trends of which we are unaware), but in other cases, common for the sorts of traits evolutionary ecologists like to study, these methods will lead to ambiguous inferences. This seemingly nihilistic conclusion does have two escape hatches. First, we must recognize that fossil data really are integral to understanding what happened in the past. This prescription is not at all novel (e.g., Doyle and Donoghue, 1987; Novacek, 1996; Springer et al., 2001), but is certainly correct — by finding ways to synthesize fossil and phylogenetic data, we will get the strongest insight on past events. Second, in many cases, the solution is to re-formulate questions so that ancestral character reconstruction is not necessary. For example, we can ask whether a trait evolves relatively often or little without needing to infer specific ancestral character states (e.g., in the Anolis habitat specialist example, many transitions must have occurred, regardless of the specific identity of ancestral nodes in the phylogeny). Similarly, statistical evaluation of whether two traits have evolved in a correlated fashion can be conducted without ancestral character state information (e.g., using independent contrasts, which in the T7 phage study discussed above was able to accurately estimate correlated evolution among characters, even 
when ancestral reconstruction of those characters was highly inaccurate [Oakley and Cunningham, 2000]).

Rates of Diversification

Early on in the phylogenetic comparative revolution, researchers realized that the shape of a phylogeny could provide information on patterns of diversification (e.g., Nee et al., 1992, 1994). For example, a phylogeny with many short branches originating near the base and many long terminal branches might indicate an early burst of speciation followed by a slowing in the rate of species increase. Many sophisticated methods have been developed to plumb a phylogeny for information on rates of diversification; the most widely used and conceptually simplest is the lineage-through-time (LTT) plot, which starts at the base of a phylogeny and tabulates the number of lineages extant at each point in time to the present. From this simple information, much can be deduced.

A shortcoming of LTT plots, as well as of other, more sophisticated, approaches, is that extinct taxa usually are not represented in phylogenies (at least not in those based on extant taxa). Each extant species is evidence of at least one speciation event in the past, but all extinctions must be inferred. Indeed, based on branch lengths and topology, many methods estimate not only rates of diversification (speciation - extinction), but also rates of speciation and extinction separately. At face value, LTT plots suggest an ever-increasing species richness through time (Ricklefs, 2007), yet we know that can't be, because clades wax and wane through time (Gould et al., 1977; German et al., 1987; Foote, 2007). Although some topologies have been interpreted as suggestive of past mass extinction events (e.g., Ricklefs and Bermingham, 2001), current approaches generally cannot infer an ongoing decline in species richness.

Recently, Quental and Marshall (2010) investigated the efficacy of these methods. Using cetaceans, which thanks to their size and aquatic habits, have an extraordinarily complete fossil record, these authors compared diversity dynamics through time based on the fossil record versus those inferred from a molecular phylogenetic study that included almost every living cetacean species (Steeman et al., 2009). The molecular record suggested a constant and ongoing rate of increase in species richness throughout the history of this lineage with no extinction. These suggestions, however, are flatly contradicted by the fossil record: in fact, the number of cetacean species has at best held constant, and probably declined sharply, over the last 12 million years, in contrast to the inferred steady increase in species number. Moreover, rather than a phylogenetically-inferred pause in diversification, speciation increased sharply in the period from 20-25 mya, and many cetacean lineages have gone extinct. Why were the inferences from the molecular phylogeny so far off-base? Quental and Marshall argue that these methods make a series of assumptions, such as that rates of diversification are uniform through time and across clades, that are usually violated. In contrast, evolutionary diversification is usually much more variable and inconsistent, such that the relatively simple assumptions of these methods cannot possibly correspond to the variation exhibited by real clades. Quental and Marshall conclude (2010, p.439): "There are usually several alternative processes that can account for any given [phylogenetic] pattern [of species diversity through time]....It is exceedingly hard to reach firm conclusions about the rates and processes of diversification from molecular phylogenies ... without input from the fossil record."

The ability to estimate rates of diversification from a phylogeny is also hampered by lack of data on extinct taxa and the assumption that species richness increases inexorably through time (Rabosky, 2009; Ricklefs, 2009). If, in fact, species richness is extrinsically limited, 
perhaps by some sort of carrying capacity, then once that limit is hit, rates of speciation and extinction will be the same. At this point, species richness would no longer increase and the inferred rate of diversification would decline with the age of the clade. As a result, even if diversification dynamics were identical, diversification rates inferred for clades of different ages would be different - the longer the clade existed at the carrying capacity, the lower its rate of diversification. In such circumstances, which may well be the norm, inferences about speciation and extinction based on the overall rate of at which diversification has occurred will not be reliable (Liow et al., 2010; Rabosky, 2010a).

Phylogenies have also been used specifically to estimate extinction rates. Although it may seem paradoxical that one could infer the occurrence of extinction from data on extant species, the underlying rationale is that if extinction rates are high, most extant lineages will be young (i.e., recently derived from their most recent common ancestors), whereas if it low, many old lineages will still exist. Many studies, including my own work on Caribbean Anolis (Losos and Schluter, 2000), have inferred a rate of zero for extinction (Purvis, 2008). This, of course, seems odd - surely some species go extinct during a clade's history. As Fitzjohn (2010, p.59) noted: "Accurate detection of extinction requires that we determine the rate at which species fail to appear in our phylogeny, which is a difficult task." Rabosky (2010b, Evolution) recently reexamined the utility of phylogenies for estimating extinction, and his title says it all: "Extinction Rates Should Not be Estimated from Molecular Phylogenies." The reason is simple. Although these methods can accurately estimate extinction rates when their model assumptions are met, they are very sensitive to deviations from these assumptions, such as the existence of temporal or among-clade variation in rates of diversification, and when the assumptions are violated, the methods perform poorly. Echoing Quental and Marshall, Rabosky concludes (p. 1822): "the estimation of meaningful extinction rates from data on living species only is a challenging problem that may be insoluble. The results of this study argue strongly for better integration of paleontological data with molecular phylogenetic studies of diversification."

A great deal of work has been conducted in recent years using molecular phylogenies to draw inferences about a clade's diversity dynamics through time. My view is that recent work is showing that this enterprise is assumption laden and highly problematical. My expectation is that, like ancestor reconstruction, we will have to realize that the inferences we can confidently derive about patterns and rates of diversification drawn from phylogenies often are limited, and that fossils really are indispensable for understanding how species diversification has occurred through time.

Phylogenetic Approaches Are Not Suitable For Traits That Evolve Frequently and Substantially $\underline{\text { Within Species }}$

As discussed above, phylogenetic approaches are most powerful when phylogenetic effect exists. Except when trait space is unbounded or divergence of related species is correlated, the existence of phylogenetic effect implies a relatively low rate of character evolution relative to the rate of cladogenesis, such that closely related species tend to be phenotypically similar. Consequently, with the same exceptions, we would expect that phylogenetic methods would not be informative about traits that evolve too readily within a species, because such traits would tend to differ relatively greatly among closely related species, leaving little imprint of the historical record. 
A case in point is the study of the geography of speciation. Ernst Mayr popularized the view that speciation almost always occurs in allopatry, and ever since then, controversy has raged, sometimes more fiercely than others, about how likely speciation is to occur in other geographical contexts. Quickly after the emergence of phylogenetic thinking, researchers suggested that phylogenies could be used to study the geography of speciation (Lynch, 1989; Brooks and McLennan, 1991). By reconstructing the ancestral ranges of species, one could infer whether two species had been sym-, allo-, para- or peripatric at the time they diverged. For sister taxa, the procedure was straightforward: species allopatric today were assumed to be allopatric at the time they diverged, whereas sister taxa sympatric today were presumed to have been sympatric when speciation occurred, and so on for other geographic patterns. For deeper nodes in a phylogeny, the geographic range of ancestral taxa had to be estimated, often as the sum of the ranges of all descendant species, and then sister taxa compared. Protocols varied, and more sophisticated approaches subsequently have been developed (Barraclough and Vogler, 2000; Fitzpatrick and Turelli, 2006), but a basic assumption is that we can infer the geographic range of a species at the time speciation occurred based on its range today.

The problem is that the fossil record indicates that geographic ranges are far from static, but rather change greatly over short periods of time. For example, the geographic ranges of many North American mammals today do not overlap at all where they occurred 10,000 years ago, and many species that were sympatric at that time are today allopatric. Similar patterns also have been documented in Europe and Australia, indicating that this is not a North American or Holarctic Ice Age phenomenon (Graham, 1986). Clearly, using modern-day geographic ranges to infer the geographic range and extent of sympatry of species only 10,000 years ago is a dicey enterprise; trying to do so in the more distant past when speciation occurred is even more problematic.

The fluidity of geographic ranges was demonstrated in another way by Foote et al. (2007) in an examination of the ranges of New Zealand marine mollusks throughout the Cenozoic. They found that almost all species showed considerable variation in the size of their ranges throughout the course of their existence (Figure 10; see also Liow and Stenseth, 2007).

Given this microevolutionary rapidity of geographic range change, occurring in a bounded geographical space and usually occurring independently in related species, it seems clear that phylogenetic information provides little useful insight into the extent of overlap of ancestral geographic ranges for extant sister species; inferring speciation events deeper in the phylogeny, with the requisite inference of geographical range overlap of ancestral taxa, is even less reliable (Losos and Glor, 2003). To unravel the mysteries of the geographic mode of speciation, we will need to focus research at the appropriate, microevolutionary time-scale.

I suspect, more generally, that many population level phenomena—population size, density, heterozygosity - are probably similar to geographic range in their microevolutionary lability, and thus probably also fall outside of the scope of phylogenetic analysis. For example, population size of many species can vary substantially over short periods of time (Connell and Sousa, 1983) and exhibits little phylogenetic effect in at least some clades (Ricklefs, 2011a,b).

\section{Phylogenies Depict Patterns, Not Processes}

Most phylogenetic patterns potentially could be explained by more than one process (Derrickson and Ricklefs, 1988; McKitrick, 1993; Blomberg and Garland, 2002). For example, high values of phylogenetic signal can result if the rate of niche shifts is great early in a radiation 
and decreases through time (perhaps as a result of colonization of an empty island and filling up of ecological niches through time), but also if the rate of genetic drift decreases through time (perhaps as a result of decreased mutation rates or increased population sizes [Revell et al., 2008]). Or, to cite another example, the rate of species diversification through time may be inferred to decline if niches become filled, inhibiting speciation or increasing extinction, or because speciation occurs primarily by means of vicariant splitting, and as species' ranges become smaller, they become less likely to split again (Pigot et al., 2010). In both examples, two very distinct scenarios, relying on different evolutionary mechanisms, can produce the same phylogenetic pattern.

Phylogenetic pattern can be equated with evolutionary process only in cases in which a given pattern could only plausibly result from a single process. In some cases, this may be true. For example, in comparisons of DNA sequence variation across species in a phylogeny, when the rate of non-synonymous changes is significantly different than expected given the rate of synonymous changes, the conclusion that natural selection is responsible is reasonable, especially given that other evolutionary processes that could produce such a pattern are generally implausible (Yang and Bielawski, 2000; Nielsen, 2005). Nonetheless, I suggest that in most situations, this is not the case and that, in fact, there are usually multiple evolutionary scenarios, involving very different evolutionary mechanisms, that could produce a given phylogenetic pattern. ${ }^{10}$

Phylogeny is a pattern, not a causal mechanism

Unfortunately, phylogeny is often treated as if it were a causal mechanism, rather than a pattern. Moreover, some analytical frameworks for investigating correlates of interspecific trait variation contrast present-day conditions versus phylogenetic relationships as potential explanators. For example:

"Significant phylogenetic influences on leaf traits were observed in Shorea at GPNP, but the relative importance of phylogeny compared to habitat in determining leaf traits differed among traits."

But phylogeny and present-day conditions are not mutually exclusive explanations; adaptation to different habitats might explain ecophysiological traits in leaves regardless of whether each species had independently evolved its own adaptive traits or whether clades of species shared the same adaptive response to living in the same environment (which would be attributed to "phylogeny" [Westoby et al., 1995]).

The bottom line here is that phylogeny is the pattern of evolutionary history. In the context of this history, we can investigate the responsible causal mechanisms. But phylogeny does not cause anything and should not be treated as if it does (see also Blomberg and Garland, 2002; Shanahan, 2011).

\section{Phylogenetic Constraint}

To my mind, "phylogenetic constraint" is one of the most misleading terms in evolutionary biology, and I recommend its use be dropped. Evolutionary biologists have long debated the importance of constraints, defined as some intrinsic or extrinsic feature that biases

\footnotetext{
${ }^{10}$ This is not to say that phylogenies are not useful in eliminating some potential possibilities, or in showing that some processes are more likely than others.
} 
evolution to occur more likely in some ways than in others. Constraints can be those that affect the production of phenotypic variation (e.g., developmental, genetic, and architectural constraints ${ }^{11}$ ) or those that affect what happens to variation once produced (e.g., selective constraints ${ }^{12}$ ). These are all similar in that they can constrain or bias the direction of evolution by making some types of change more likely to occur than others.

How, then, could phylogeny be a constraint? Of course, it can't. Phylogeny is just the pattern of evolutionary change through time; in itself, phylogeny cannot constrain anything. "Phylogenetic constraint" is shorthand for saying that closely related species have failed to evolve in some way because they share some feature - perhaps a developmental system, genetic covariance, or selective environment - that has constrained evolutionary change; in this sense, "phylogenetic constraint" is no different than "phylogenetic effect." Rather than explaining how and why evolution has been constrained, recognition of a phylogenetic constraint serves to identify that a constraint exists, and to prompt investigation into the mechanistic basis of the constraint. Identification of a phylogenetic constraint, then, is not an answer to what happened, but an invitation to conduct further research (Derrickson and Ricklefs, 1988; McKitrick, 1993; Blomberg and Garland, 2002; see also discussion of "phylogenetic inertia" in Shanahan, 2011).

If all researchers understood this meaning and realized that a "phylogenetic constraint" is not another type of constraint, on par with developmental, genetic, architectural, functional and selective constraints, no problem would exist. But the literature suggests that this is not the case. In many cases, phylogenetic constraint is pitted against present day selective environment as an explanation for interspecific variation in some trait:

"To investigate whether social structuring in this species is a response to ecological conditions or is phylogenetically constrained..."

"Exine Micromorphology of Orchidinae (Orchidoideae, Orchidaceae): Phylogenetic Constraints or Ecological Influences?"

"The consistent level of hypothermia at varying ambient temperatures suggests that either nonenergetic costs or phylogenetic constraints prevent deeper hypothermia in cold."

"Flowering, fruiting and seed germination in Chilean rain forest Myrtaceae: ecological and phylogenetic constraints"

As in the previous section, these statements seem to imply that phylogeny is a mechanistic process constraining evolution. Of course, it cannot, and what these statements do is contrast present-day ecological (=selective) conditions versus a historical pattern in which closely related species are phenotypically similar. But because closely related species can share the same ecological attributes, this is a false dichotomy that contrasts process (selection) with historical pattern (phylogeny) - ecology (selection) can be responsible for species' phenotypes, regardless of whether species' phenotypes are similar or different from those of closely related species.

${ }^{11}$ Of course, these are not independent, as development and phenotype are the result of genes.

${ }^{12}$ Although Williams $(1992$, p. 80) reasonably asked "If selection is listed among the [types of] constraints, then what is it that is constrained?" 
What, then, is a phylogenetic constraint? It is simply the observation that related species share a constraint (including common selective environment). Documenting such a phylogenetic effect reveals the historical pattern, and can suggest hypotheses about its cause, but by itself, such documentation cannot distinguish among the possible types of constraint that might be operating.

\section{Phylogenetic Niche Conservatism}

The last few years have seen an explosion of research into phylogenetic niche conservatism (PNC), the phenomenon that species tend to retain ancestral ecological niche characteristics (Cooper et al., 2010; Wiens et al., 2010). As with "phylogenetic constraint," confusion exists over whether PNC is a pattern or a process. Wiens and Donoghue (2004) put it well: "Although niche conservatism can be seen as a pattern or outcome rather than a process, it can be actively maintained by microevolutionary forces over time [Wiens, 2004]." In other words, PNC is the documentation of relatively little ecological change between ancestor and descendant, often — but not always (Kozak and Wiens, 2010; Wiens et al., 2010) — recognized by unusually great ecological similarity among closely related species (Losos, 2008; see review of different conceptions and tests of PNC in Cooper et al., [2010]). Such documentation identifies a pattern, but does not explain it, because many different processes - stabilizing selection, or any type of constraint mentioned above - could preclude clade members from diversifying ecologically.

In a manner completely analogous to that seen with phylogenetic constraint, however, many workers treat PNC as an evolutionary process:

" $52.4-67 \%$ of indriid body size variation is explained by phylogenetic niche conservation... Researchers ... should be aware that some ecology-phenotype relationships are best explained as the result of the synergistic effects of ecology and phylogeny."

"phylogenetic niche conservatism has played a role in the persistence of deep complex morphophysiological dormancy in the three western North American species of Osmorhiza"

"We provide evidence that phylogenetic niche conservatism has been responsible for the maintenance of aquatic-associated larval morphological character states"

Of course, PNC does not cause anything. It cannot explain why species have the same niche as their ancestors, because it is simply documentation of exactly that. This is not to say that documenting PNC is not important. Quite the contrary, its documentation leads to hypotheses about why it might occur. Moreover, the existence of the phenomenon of PNC has important implications for understanding patterns in many fields, including biogeography, speciation, community structure, conservation biology, and even ecosystem ecology (Donoghue, 2008; Wiens et al., 2010). Nonetheless, there is a difference between a process (or causal mechanism) and a pattern (or phenomenon). ${ }^{13}$

\footnotetext{
${ }^{13}$ Wiens and colleagues (Wiens, 2008; Wiens and Graham, 2005; Wiens et al., 2010) refer to niche conservatism as a process. What they mean is that the existence of niche conservatism has consequences for many aspects of biology. For example, if species tend to remain in their ancestral niche, then environmental change can lead to
} 
This discussion of phylogenetic constraints and PNC highlights what we can and cannot learn from phylogenies. Phylogenies can give us clues about the pattern of evolution through time, but in themselves, they can rarely explain why evolution occurred as it did. Usually, there are multiple possible process-based scenarios - oftentimes very different - that could produce the same pattern. Only when there is just one possible process that could produce a given pattern can we confidently infer process from pattern.

By contrast, the opposite is more often true. Although a given phylogenetic pattern may be produced by many processes, a given process may tend to produce only a single pattern; hence, failure to find evidence of that pattern may effectively disprove that hypothesis. For example, coevolution between two traits should lead to a pattern in which evolutionary change in the two traits is tightly coupled; failure to find such coupling would suggest that the traits do not co-evolve. Much more frequently, phylogeny will serve as a great tool to generate hypotheses about process, but not to test them directly.

\section{Conclusions}

My thoughts here can be boiled down to four take-home messages:

1) Some past events are lost in the fog of time (cf. Williams, 1969; Gould, 1995) — because of their pace of change, some aspects of history are not recoverable by examination of phylogenies. That is, regardless of the sophistication of our analytical methods, we will not be able to use phylogenetic information to say with any confidence what happened in these cases. In these cases, data from fossils may be the best hope for making historical inferences.

2) Evolution is messy. Rates, direction, and mode of evolution vary through time and among clades and characters, and this inconstancy itself will often be unpredictable and haphazard. Phylogenetic methods that ignore this variation will often produce inaccurate and misleading results. As a result, researchers must embrace statistical approaches that assess such variation, rather than assuming constancy. Many such methods have been developed recently, with more on the way - the extent to which such methods can adequately deal with variability remains to be seen. Along these lines, a posteriori analyses of absolute model fit to see whether the models are doing a reasonable job of reconstructing major features of the observed data should become routine. For example, given a fitted model, simulations can be employed to determine whether the patterns that come out bear some resemblance to the empirical data (e.g., Rabosky, 2010; Rabosky and Glor, 2010).

3) Under most circumstances, the connection between phylogenetic pattern and evolutionary process will be tenuous. In many, perhaps most, cases, a multitude of disparate scenarios involving different evolutionary processes can produce the same phylogenetic pattern. Phylogenetic patterns can suggest that some scenarios are more likely than others, and in some cases can even convincingly disprove some hypotheses (e.g., when a trait is inferred to have pre-dated the appearance of the selective situation hypothesized to have driven caused its evolution). Nonetheless, as a general rule, it is important to remember that phylogenies describe patterns, onto which evolutionary processes usually map only imperfectly.

population fragmentation, increasing the likelihood of allopatric speciation (Wiens, 2004). I think of a process as a mechanism or causal agent, and to my mind, just because the existence of niche conservatism has downstream effects does not make niche conservatism a process, even if its existence is a necessary precondition for some process-such as natural selection or genetic drift-to produce a particular outcome. 
4) Conversely, combining phylogenetic approaches with the study of ongoing evolutionary process in extant taxa may be the most fruitful approach for inferring how evolution operates and what happened in the past. A number of workers (e.g., Grant, 1986; Cleland, 2002), including me (Losos, 2007, 2009), have likened the study of evolutionary phenomena to a detective story, in which there is no smoking gun, and in which disparate clues have to be drawn together to provide the most plausible hypothesis of what happened. For example, phylogenetic hypotheses might suggest that coexistence with other species has driven evolutionary change; ecological experiments among extant species could then be used to test whether such species have detectable ecological effects on each other and, if so, whether such interactions drive microevolutionary change in the predicted direction. Because present-day circumstances are imprecise surrogates for past conditions, this approach is not without difficulties, but such a synthesis is probably the best means to unite phylogenetic pattern and evolutionary process.

Finally, I want to re-emphasize that this jeremiad should not be taken as a rejection of phylogenetics. Evolutionary biology has moved forward immeasurably in the last quarter century, and the emergence of tree-thinking has played a major role. Phylogenetics is a powerful tool for understanding evolution, but it is not omnipotent. Recognition of its strengths and limits, and combination with other approaches, is the best means of advancing our understanding of evolutionary phenomena.

\section{Acknowledgments}

I am grateful to many people who took the time to read and comment on one or multiple drafts of this manuscript. Most disagreed with some of it, some with most of it, and possibly a few with all of it. I believe their comments have greatly improved this paper, and I hope they agree. Thanks to the Adams-Valenzuela-Serb Joint Lab Discussion Group at Iowa State University, N. Cooper, C. Cunningham, C. Davis, M. Donoghue, B. Forrestel, R. Glor, L. Harmon, the R. Langerhans Lab, L. Mahler, M. Noor, D. Rabosky, L. Revell, and P. Wainwright. Thanks also to M. Foote, J. Knouft, L. Revell, and M. Woolley for assistance with figures. And, of course, thanks to the membership of the American Society of Naturalists for electing me. It has been an honor and a privilege to serve as President. 


\section{$\underline{\text { Literature Cited }}$}

Ackerly, D.D., and M.J. Donoghue. 1998. Leaf size, sapling allometry, and Corner's rules: phylogeny and correlated evolution in maples (Acer). American Naturalist 152:767-791.

Albert, E.M., D. San Mauro, M. Garcia-Paris, L. Ruber, and R. Zardoya. 2009. Effect of taxon sampling on recovering the phylogeny of squamate reptiles based on complete mitochondrial genome and nuclear gene sequence data. Gene 441:12-21.

Ane, C. 2008. Analysis of comparative data with hierarchical autocorrelation. Annals of Applied Statistics 2:1078-1102.

Barraclough, T.G., and A.P. Vogler. 2000. Detecting the geographical pattern of speciation from species-level phylogenies. American Naturalist 155:419-434.

Bjørklund, M. 1997. Are 'comparative methods' always necessary? Oikos 80:607-612.

Blomberg, S.P., and T. Garland. 2002. Tempo and mode in evolution: phylogenetic inertia, adaptation and comparative methods. Journal of Evolutionary Biology 15:899-910.

Blomberg, S.P., T. Garland, and A.R. Ives. 2003. Testing for phylogenetic signal in comparative data: behavioral traits are more labile. Evolution 57:717-745.

Brooks, D.R. 1985. Historical ecology - a new approach to studying the evolution of ecological associations. Annals of the Missouri Botanical Garden 72:660-680.

Brooks, D.R., and D.A. McLennan. 1991. Phylogeny, ecology, and behavior : a research program in comparative biology. University of Chicago Press, Chicago.

Butler, M.A., and A.A. King. 2004. Phylogenetic comparative analysis: a modeling approach for adaptive evolution. American Naturalist 164:683-695.

Carpenter, J.M. 1992. Comparing methods. Cladistics 8:191-195.

Cavender-Bares, J., D.D. Ackerly, D.A. Baum, and F.A. Bazzaz. 2004. Phylogenetic overdispersion in Floridian oak communities. American Naturalist 163:823-843.

Cavender-Bares, J., K.H. Kozak, P.V.A. Fine, and S.W. Kembel. 2009. The merging of community ecology and phylogenetic biology. Ecology Letters 12:693-715.

Chang, B.S.W., K. Jonsson, M.A. Kazmi, M.J. Donoghue, and T.P. Sakmar. 2002. Recreating a functional ancestral archosaur visual pigment. Molecular Biology and Evolution 19:1483-1489.

Cleland, C.E. 2002. Methodological and epistemic differences between historical science and experimental science. Philosophy of Science 69:474-496. 
Clutton-Brock, T.H., and P.H. Harvey. 1984. Comparative approaches to investigating adaptation. Pages 7-29 in J.R. Krebs and N.B. Davies, eds. Behavioral ecology: an evolutionary approach. Sinauer Associates, Sunderland.

Connell, J.H., and W.P. Sousa. 1983. On the evidence needed to judge ecological stability or persistence. American Naturalist 121:789-824.

Cooper, N., W. Jetz, and R.P. Freckleton. 2010. Phylogenetic comparative approaches for studying niche conservatism. Journal of Evolutionary Biology 23:2529-2539.

Cooper, N., J. Rodriguez, and A. Purvis. 2008. A common tendency for phylogenetic overdispersion in mammalian assemblages. Proceedings of the Royal Society B-Biological Sciences 275: 2031-2037.

Cracraft, J. 1981. Pattern and process in paleobiology: the role of cladistic analysis in systematic paleontology. Paleobiology 7:456-468.

Dean, A.M., and J.W. Thornton. 2007. Mechanistic approaches to the study of evolution: the functional synthesis. Nature Reviews Genetics 8:675-688.

Derrickson, E.M., and R.E. Ricklefs. 1988. Taxon-dependent diversification of life-history traits and the perception of phylogenetic constraints. Functional Ecology 2:417-423.

Donoghue, M.J. 2008. A phylogenetic perspective on the distribution of plant diversity. Proceedings of the National Academy of Sciences of the United States of America 105:1154911555.

Doyle, J.A., and M.J. Donoghue. 1987. The importance of fossils in elucidating seed plant phylogeny and macroevolution. Review of Palaeobotany and Palynology 50:63-95.

Felsenstein, J. 1985. Phylogenies and the comparative method. American Naturalist 125:1-15.

Felsenstein, J. 1988. Phylogenies and quantitative characters. Annual Review of Ecology and Systematics 19:445-471.

Finarelli, J.A., and J.J. Flynn. 2006. Ancestral state reconstruction of body size in the Caniformia (Carnivora, Mammalia): the effects of incorporating data from the fossil record. Systematic Biology 55:301-313.

FitzJohn, R.G. 2010. Quantitative traits and diversification. Systematic Biology 59:619-633.

Fitzpatrick, B.M., and M. Turelli. 2006. The geography of mammalian speciation: mixed signals from phylogenies and range maps. Evolution 60:601-615. 
Foote, M. 2007. Symmetric waxing and waning of marine invertebrate genera. Paleobiology 33:517-529.

Foote, M., J.S. Crampton, A. G. Beu, B.A. Marshall, R.A. Cooper, P.A. Maxwell, and I. Matcham. 2007. Rise and fall of species occupancy in Cenozoic fossil mollusks. Science $\underline{318: 1131-1134 .}$

Freckleton, R.P., P.H. Harvey, and M. Pagel. 2002. Phylogenetic analysis and comparative data: a test and review of evidence. American Naturalist 160:712-726.

Frumhoff, P.C., and H.K. Reeve. 1994. Using phylogenies to test hypotheses of adaptation - a critique of some current proposals. Evolution 48:172-180.

Garland, T., P.E. Midford, and A.R. Ives. 1999. An introduction to phylogenetically based statistical methods, with a new method for confidence intervals on ancestral values. American Zoologist 39:374-388.

Graham, C.H., S.R. Ron, J.C. Santos, C.J. Schneider, and C. Moritz. 2004. Integrating phylogenetics and environmental niche models to explore speciation mechanisms in dendrobatid frogs. Evolution 58:1781-1793.

Gittleman, J.L. 1981. The phylogeny of parental care in fishes. Animal Behaviour 29:936-941.

Goldberg, E.E., and B. Igic. 2008. On phylogenetic tests of irreversible evolution. Evolution $62: 2727-2741$.

Gould, S.J. 1995. Dinosaur in a Haystack: Reflections in Natural History. Three Rivers Press, New York.

Gould, S.J., D.M. Raup, J.J. Sepkoski Jr., T.J.M. Schopf, and D.S. Simberloff. 1977. The shape of evolution: a comparison of real and random clades. Paleobiology 3:23-40.

Gould, S.J., N.L. Gilinsky, and R.Z. German. 1987. Asymmetry of lineages and the direction of evolutionary time. Science 236:1437-1441.

Grandcolas, P., P. Deleporte, and L. Desutter-Grandcolas. 1997. Testing evolutionary processes with phylogenetic patterns: test power and test limitations. Pages 53-71 in P. Grandcolas, ed. The origin of biodiversity in insects: phylogenetic tests of evolutionary scenarios. Mémoires du Museum national d'Histoire naturelle, Paris.

Grant, P.R. 1986. Ecology and evolution of Darwin's finches. Princeton University Press, Princeton.

Greene, H.W., and G.M. Burghardt. 1978. Behavior and phylogeny - constriction in ancient and modern snakes. Science 200:74-77. 
Hansen, T.F. 1997. Stabilizing selection and the comparative analysis of adaptation. Evolution 51:1341-1351.

Harmon, L.J., J.B. Losos, T.J. Davies, R.G. Gillespie, J.L. Gittleman, W.B. Jennings, K.H. Kozak, M.A. McPeek, F. Moreno-Roark, T.J. Near, A. Purvis, R.E. Ricklefs, D. Schluter, J.A. Schulte II, O. Seehausen, B.L. Sidlauskas, O. Torres-Carvajal, J.T. Weir, and A.O. Mooers. 2010. Early bursts of body size and shape evolution are rare in comparative data. Evolution $64: 2385-2396$.

Harvey, P.H., and M.D. Pagel. 1991. The comparative method in evolutionary biology. Oxford University Press, Oxford.

Huey, R.B., and A.F. Bennett. 1987. Phylogenetic studies of coadaptation - preferred temperatures versus optimal performance temperatures of lizards. Evolution 41:1098-1115.

Hull, D. 1988. Science as a process. University of Chicago, Chicago.

Johnson, A.D., M. Drum, R.F. Bachvarova, T. Masi, M.E. White, and B.I. Crother. 2003. Evolution of predetermined germ cells in vertebrate embryos: implications for macroevolution. Evolution and Development 5:414-431.

Kozak, K.H., and J.J. Wiens. 2010. Accelerated rates of climatic-niche evolution underlie rapid species diversification. Ecology Letters 13:1378-1389.

Kraft, N.J.B., W.K. Cornwell, C.O. Webb, and D.D. Ackerly. 2007. Trait evolution, community assembly, and the phylogenetic structure of ecological communities. American Naturalist 170:271-283.

Larson, A., and J.B. Losos. 1996. Phylogenetic systematics of adaptation. Pages 187-220 in M.R. Rose and G.V. Lauder, eds. Adaptation. Academic Press, San Diego.

Lauder, G.V. 1981. Form and function: structural analysis in evolutionary morphology. Paleobiology 7:430-442.

Liberles, D.A. 2007. Ancestral sequence reconstruction. Oxford University Press, Oxford.

Liow, L.H., and N.C. Stenseth. 2007. The rise and fall of species: implications for macroevolutionary and macroecological studies. Proceedings of the Royal Society B-Biological Sciences 274:2745-2752.

Liow, L.H., T.B. Quental, and C.R. Marshall. 2010. When can decreasing diversification rates be detected with molecular phylogenies and the fossil record? Systematic Biology 59:646-659.

Losos, J.B. 1990. Ecomorphology, performance capability, and scaling of West Indian Anolis lizards: an evolutionary analysis. Ecological Monographs 60:369-388. 
Losos, J.B. 1992. The evolution of convergent community structure in Caribbean Anolis communities. Systematic Biology 41:403-420.

Losos, J.B., T.R. Jackman, A. Larson, K. de Queiroz, and L. Rodríguez-Schettino. 1998. Historical contingency and determinism in replicated adaptive radiations of island lizards. Science 279:2115-2118.

Losos, J.B. 1999. Uncertainty in the reconstruction of ancestral character states and limitations on the use of phylogenetic comparative methods. Animal Behaviour 58:1319-1324.

Losos, J.B. 2007. Detective work in the west indies: integrating historical and experimental approaches to study island lizard evolution. BioScience 57:585-597.

Losos, J.B. 2008. Phylogenetic niche conservatism, phylogenetic signal and the relationship between phylogenetic relatedness and ecological similarity among species. Ecology Letters 11:995-1007.

Losos, J.B. 2009. Lizards in an evolutionary tree: ecology and adaptive radiation of anoles. University of California Press, Berkeley.

Losos, J.B., and R.E. Glor. 2003. Phylogenetic comparative methods and the geography of speciation. Trends in Ecology \& Evolution 18:220-227.

Losos, J.B., and D. Schluter. 2000. Analysis of an evolutionary species-area relationship. Nature 408:847-850.

Lynch, J.D. 1989. The gauge of speciation: on the frequency of modes of speciation. Pages 527553 in D. Otte and J.A. Endler, eds. Speciation and its consequences. Sinauer Associates, Sunderland.

MacLeod, N. 2001. The role of phylogeny in quantitative paleobiological data analysis. Paleobiology 27:226-240.

Maddison, W.P. 2006. Confounding asymmetries in evolutionary diversification and character change. Evolution 60:1743-1746.

Maddison, W.P., P.E. Midford, and S.P. Otto. 2007. Estimating a binary character's effect on speciation and extinction. Systematic Biology 56:701-710.

Mahler, D.L., L.J. Revell, R.E. Glor, and J.B. Losos. 2010. Ecological opportunity and the rate of morphological evolution in the diversification of Greater Antillean anoles. Evolution 64:27312745 .

Mayr, E. 1976. Evolution and the Diversity of Life: Selected Essays. Belknap Press, Harvard University Press: Cambridge, MA. 
Mckitrick, M.C. 1993. Phylogenetic constraint in evolutionary theory - has it any explanatory power. Annual Review of Ecology and Systematics 24:307-330.

McNamara, K.J. 1990. Evolutionary trends. University of Arizona Press, Tucson.

Morales, E. 2000. Estimating phylogenetic inertia in Tithonia (Asteraceae): a comparative approach. Evolution 54:475-484.

Nee, S., A.O. Mooers, and P.H. Harvey. 1992. Tempo and mode of evolution revealed from molecular phylogenies. Proceedings of the National Academy of Sciences of the United States of America 89:8322-8326.

Nee, S., E.C. Holmes, R.M. May, and P.H. Harvey. 1994. Extinction rates can be estimated from molecular phylogenies. Philosophical Transactions of the Royal Society of London Series BBiological Sciences 344:77-82.

Nielsen, R. 2005. Molecular signatures of natural selection. Annual Review of Genetics 39:197218.

Novacek, M.J. 1996. Paleontological data and the study of adaptation. Pages 311-359 in M.R. Rose and G.V. Lauder, eds. Adaptation. Academic Press, San Diego.

Oakley, T.H., and C.W. Cunningham. 2000. Independent contrasts succeed where ancestor reconstruction fails in a known bacteriophage phylogeny. Evolution 54:397-405.

O'Hara, R.J. 1988. Homage to Clio, or, toward an historical philosophy for evolutionary biology. Systematic Zoology 37:142-155.

Organ, C.L., A.M. Shedlock, A. Meade, M. Pagel, and S.V. Edwards. 2007. Origin of avian genome size and structure in non-avian dinosaurs. Nature 446:180-184.

Paoli, G.D. 2006. Divergent leaf traits among congeneric tropical trees with contrasting habitat associations on Borneo. Journal of Tropical Ecology 22:397-408.

Paradis, E. 2008. Asymmetries in phylogenetic diversification and character change can be untangled. Evolution 62:241-247.

Pierce, V.A., and D.L. Crawford. 1997. Phylogenetic analysis of glycolytic enzyme expression. Science 276:256-259.

Pigot, A.L., A.B. Phillimore, I.P.F. Owens, and C.D.L. Orme. 2010. The shape and temporal dynamics of phylogenetic trees arising from geographic speciation. Systematic Biology 59:660673.

Polly, P.D. 2001. Paleontology and the comparative method: ancestral node reconstructions versus observed node values. American Naturalist 157:596-609. 
Platnick, N.I., and G. Nelson. 1978. Method of analysis for historical biogeography. Systematic Zoology 27:1-16.

Purvis, A. 2008. Phylogenetic approaches to the study of extinction. Annual Review of Ecology, Evolution, and Systematics 39:301-319.

Quental, T.B., and C.R. Marshall. 2010. Diversity dynamics: molecular phylogenies need the fossil record. Trends in Ecology \& Evolution 25:434-441.

Rabosky, D.L. 2009. Ecological limits on clade diversification in higher taxa. American Naturalist 173:662-674.

Rabosky, D.L. 2009. Heritability of extinction rates links diversification patterns in molecular phylogenies and the fossil record. Systematic Biology 58:629-640

Rabosky, D.L. 2010a. Primary controls on species richness in higher taxa. Systematic Biology 59:634-645.

Rabosky, D.L. 2010b. Extinction rates should not be estimated from molecular phylogenies. Evolution 64:1816-1824.

Rabosky, D.L., and R.E. Glor. 2010. Equilibrium speciation dynamics in a model adaptive radiation of island lizards. Proceedings of the National Academy of Sciences of the United States of America 107:22178-22183.

Revell, L.J. 2010. Phylogenetic signal and linear regression on species data. Methods in Ecology and Evolution 1:319-329.

Revell, L.J., L.J. Harmon, and D.C. Collar. 2008. Phylogenetic signal, evolutionary process, and rate. Systematic Biology 57:591-601.

Rice, N.H., E. Martínez-Meyer, and A.T. Peterson. 2003. Ecological niche differentiation in the Aphelocoma jays: a phylogenetic perspective. Biological Journal of the Linnean Society 80:369383.

Ricklefs, R.E. 2007. Estimating diversification rates from phylogenetic information. Trends in Ecology \& Evolution 22:601-610.

Ricklefs, R.E. 2009. Speciation, extinction, and diversity. Pages 257-277 in R.K. Butlin, J.R. Bridle, and D. Schluter, eds., Speciation and Patterns of Diversity. Cambridge University Press, Cambridge, UK.

Ricklefs, R.E. 2011a. Evolutionary diversification, coevolution between populations and their antagonists, and the filling of niche space. Proceedings of the National Academy of Sciences of the United States of America. In press. 
Ricklefs, R.E. 2011a. Applying a regional community concept to forest birds of eastern North America. Proceedings of the National Academy of Sciences of the United States of America. In press.

Ricklefs, R.E., and E. Bermingham. 2001. Nonequilibrium diversity dynamics of the Lesser Antillean avifauna. Science 294:1522-1524.

Ridley, M. 1983. The explanation of organic diversity: the comparative method and adaptations for mating. Oxford University Press, Oxford.

Rohlf, F.J. 2001. Comparative methods for the analysis of continuous variables: geometric interpretations. Evolution 55:2143-2160.

Rosen, D.E. 1978. Vicariant patterns and historical explanation in biogeography. Systematic Zoology 27:159-188.

Schluter, D., T. Price, A.Ø. Mooers, and D. Ludwig. 1997. Likelihood of ancestor states in adaptive radiation. Evolution 51:1699-1711.

Sessions, S.K., and A. Larson. 1987. Developmental correlates of genome size in plethodontid salamanders and their implications for genome evolution. Evolution 41:1239-1251.

Shanahan, T. 2011. Phylogenetic inertia and Darwin's higher law. Studies in History and Philosophy of Biological and Biomedical Sciences 42:60-68.

Silvertown, J., M. Dodd, D. Gowing, C. Lawson, and K. McConway. 2006a. Phylogeny and the hierarchical organization of plant diversity. Ecology 87:S39-S49.

Silvertown, J., K.J. McConway, D.J. Gowing, M.E. Dodd, M.F. Fay, J.A. Joseph, and K. Dolphin. 2006b. Absence of phylogenetic signal in the niche structure of meadow plant communities. Proceedings of the Royal Society of London Series B-Biological Sciences 273:3944.

Springer, M.S., E.C. Teeling, O. Madsen, M.J. Stanhope, W.W. de Jong. 2001. Integrated fossil and molecular data reconstruct bat echolocation. Proceedings of the National Academy of Sciences of the United States of America 98:6241-6246.

Steeman, M.E., M.B. Hebsgaard, R.E. Fordyce, S.Y.W. Ho, D.L. Rabosky, R. Nielsen, C. Rahbek, H. Glenner, M.V. Sorensen, and E. Willerslev. 2009. Radiation of extant cetaceans driven by restructuring of the oceans. Systematic Biology 58:573-585.

Sytsma, K.J., and J.C. Pires. 2001. Plant systematics in the next 50 years - re-mapping the new frontier. Taxon 50:713-732.

Vamosi, S.M., S.B. Heard, J.C. Vamosi, and C.O. Webb. 2009. Emerging patterns in the comparative analysis of phylogenetic community structure. Molecular Ecology 18:572-592. 
Vermeij, G.J. 1987. Evolution and escalation: an ecological history of life. Princeton University Press, Princeton.

Webb, C.O. 2000. Exploring the phylogenetic structure of ecological communities: an example for rain forest trees. American Naturalist 156:145-155.

Webster, A.J., and A. Purvis. 2002. Testing the accuracy of methods for reconstructing ancestral states of continuous characters. Proceedings of the Royal Society of London Series B-Biological Sciences 269:143-149.

Westoby, M., M. Leishman, and J. Lord. 1995. Issues of interpretation after relating comparative datasets to phylogeny. Journal of Ecology 83:892-893.

Wiens, J.J. 2004. Speciation and ecology revisited: phylogenetic niche conservatism and the origin of species. Evolution 58:193-197.

Wiens, J.J. 2008. Commentary on Losos (2008): Niche conservatism deja vu. Ecology Letters 11:1004-1005.

Wiens, J.J., and M.J. Donoghue. 2004. Historical biogeography, ecology, and species richness. Trends in Ecology \& Evolution 19:639-644.

Wiens, J.J., and C.H. Graham. 2005. Niche conservatism: integrating evolution, ecology, and conservation biology. Annual Review of Ecology, Evolution, and Systematics 36:519-539.

Wiens, J.J., D.D. Ackerly, A.P. Allen, B.L. Anacker, L.B. Buckley, H.V. Cornell, E.I. Damschen, T.J. Davies, J.A. Grytnes, S.P. Harrison, B.A. Hawkins, R.D. Holt, C.M. McCain, and P.R. Stephens. 2010. Niche conservatism as an emerging principle in ecology and conservation biology. Ecology Letters 13:1310-1324.

Williams, E.E. 1969. The ecology of colonization as seen in the zoogeography of anoline lizards on small islands. Quarterly Review of Biology 44:345-389.

Williams, E.E. 1972. The origin of faunas. Evolution of lizard congeners in a complex island fauna: a trial analysis. Evolutionary Biology 6:47-89.

Williams, G.C. 1992. Natural selection: domains, levels and challenges. Oxford University Press, Oxford.

Yang, Z.H., and J.P. Bielawski. 2000. Statistical methods for detecting molecular adaptation.

Trends in Ecology \& Evolution 15:496-503. 
Box 1. A Sample of Studies Exhibiting no Phylogenetic Effect

Niche overlap and habitat use in Florida oaks and English meadow plants (Cavender-Bares et al., 2004; Silvertown et al., 2006a,b)

Habitat use, activity time and prey in Cuban Anolis lizards (Losos et al., 2003)

Environmental niche as determined using Geographic Information System (GIS) methods among dendrobatid frogs, Aphelocoma jays and members of the Anolis sagrei species group (Rice et al., 2003; Graham et al., 2004; Knouft et al., 2006)

Petiole length in maples (Blomberg et al., 2003)

Sperm number in Drosophila (Blomberg et al., 2003)

Germination time in Tithonia (Morales, 2009)

Nestling period in swallows (Blomberg et al., 2003)

Mean annual temperature in Fundulus (Blomberg et al., 2003)

Abundance in sunfish (Freckleton et al., 2002)

Mandible length in tiger beetles (Freckleton et al., 2002) 
Figure 1. Phylogenetic Effect (Felsenstein, 1985)
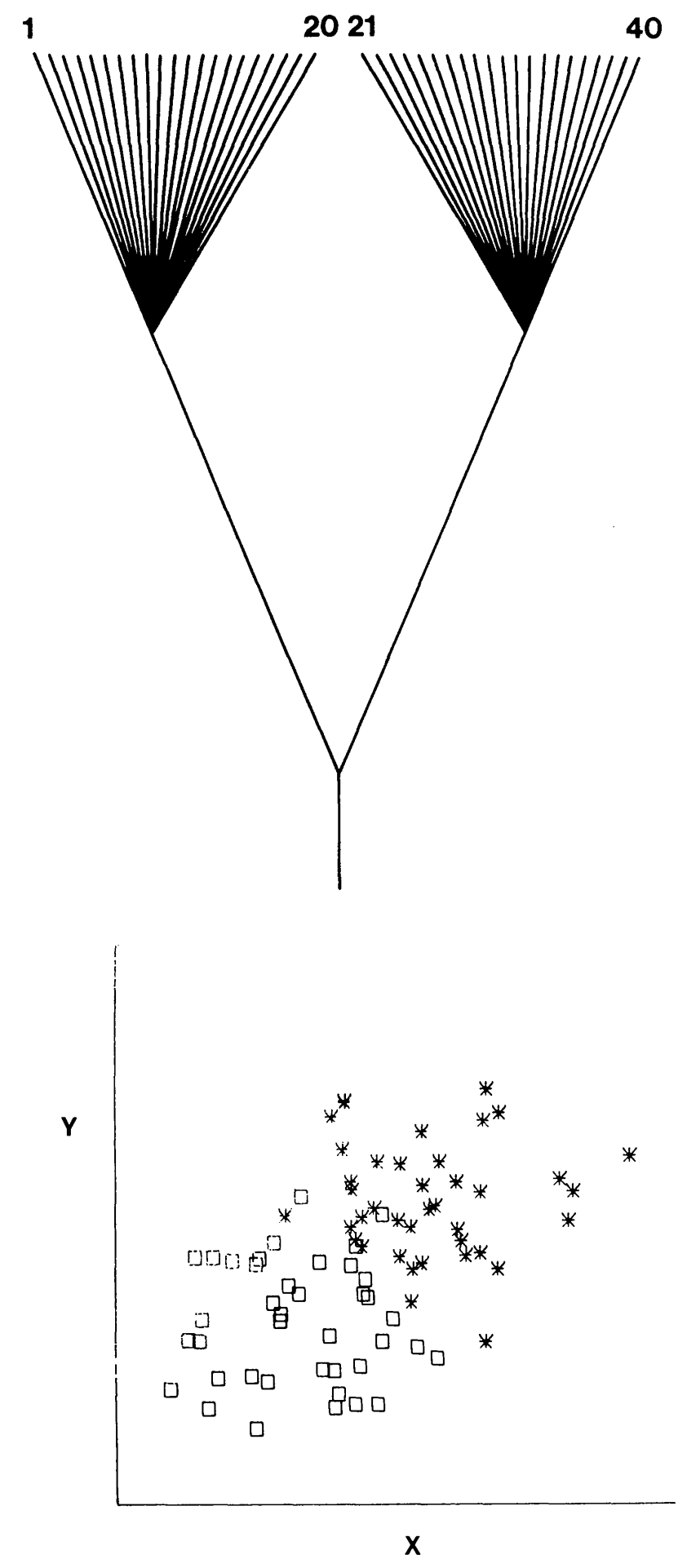
Figure 2. Evolutionary change simulated with Brownian Motion character evolution.

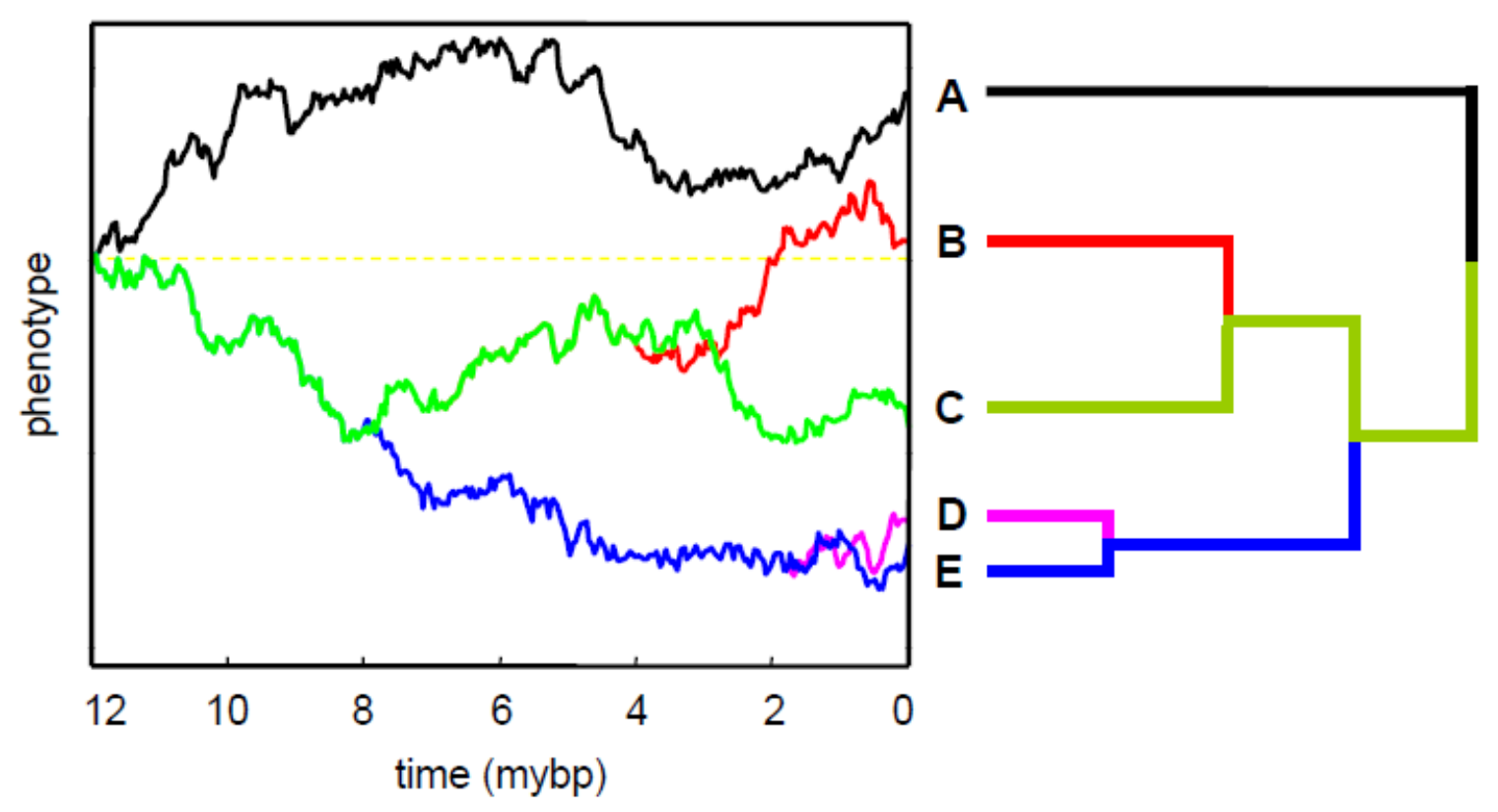


Figure 3. Evolutionary change simulated with three different selective optima.

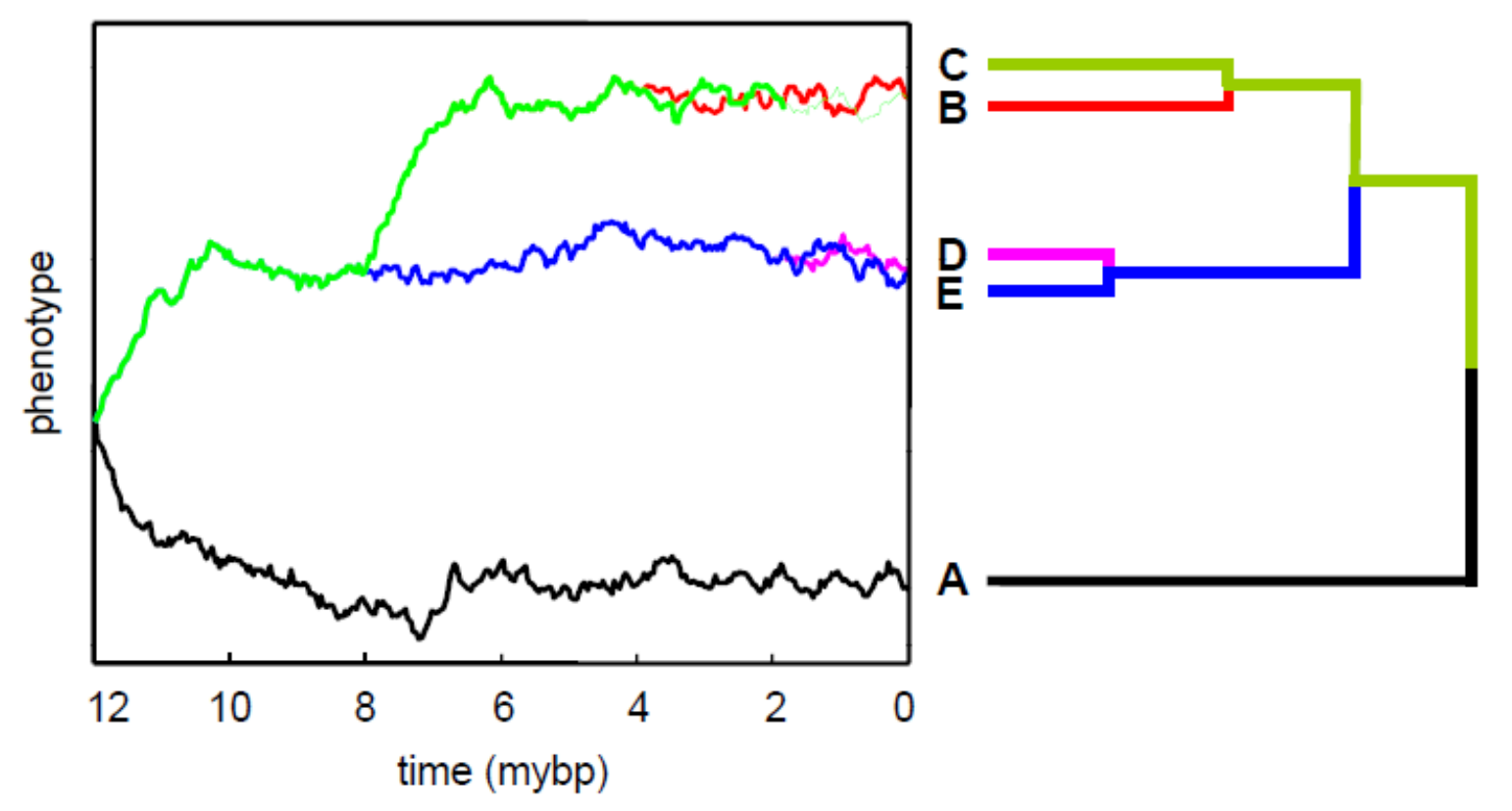


Figure 4. Example of Ancestor Reconstruction
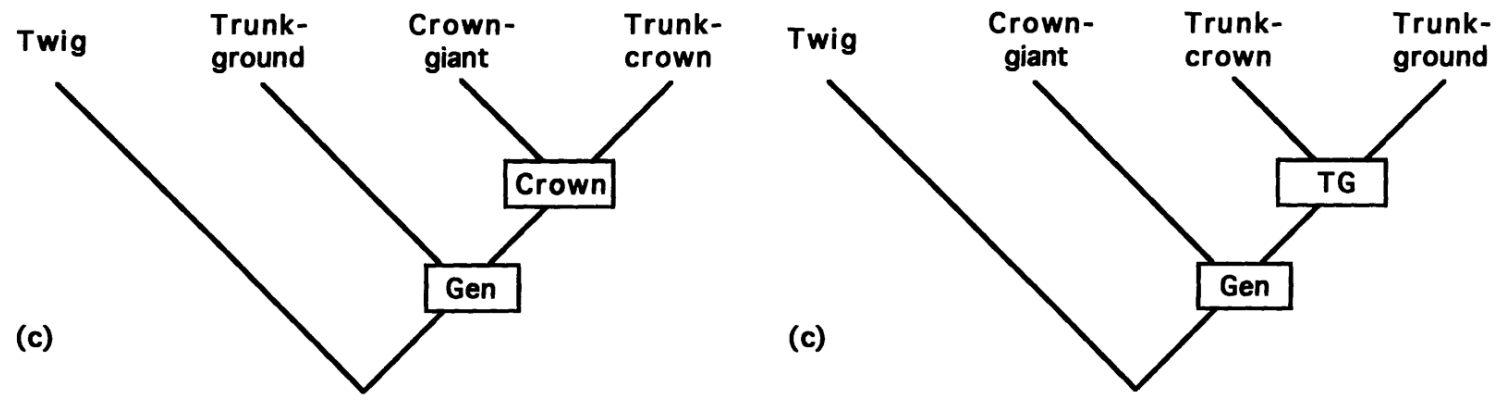
Figure 5. Different scenarios for the evolution of habitat specialists in Greater Antillean Anolis lizards. In the most parsimonious scenario (a), 17 transitions are required and the trunk-ground specialist evolves relatively late in the sequence. However, an alternative scenario in which trunk-ground anoles are the first ecomorph to evolve only requires one additional evolutionary transition (modified from Losos et al., 1998).

a)

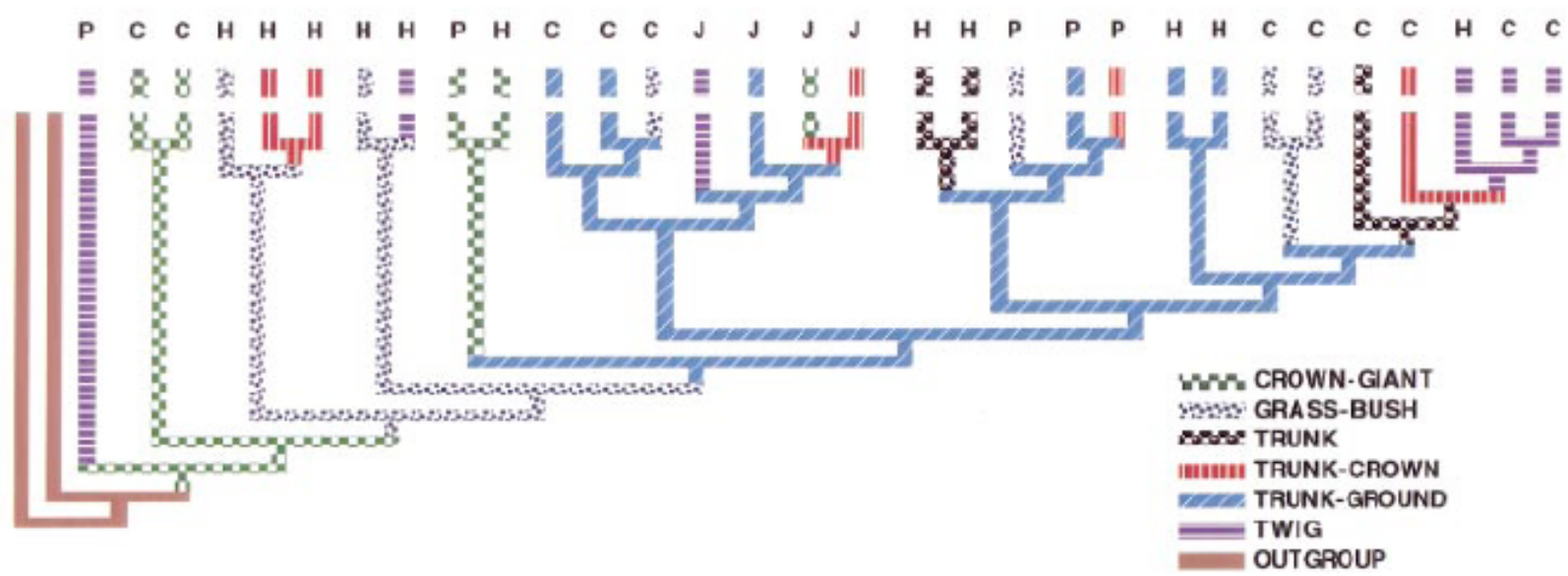

b)

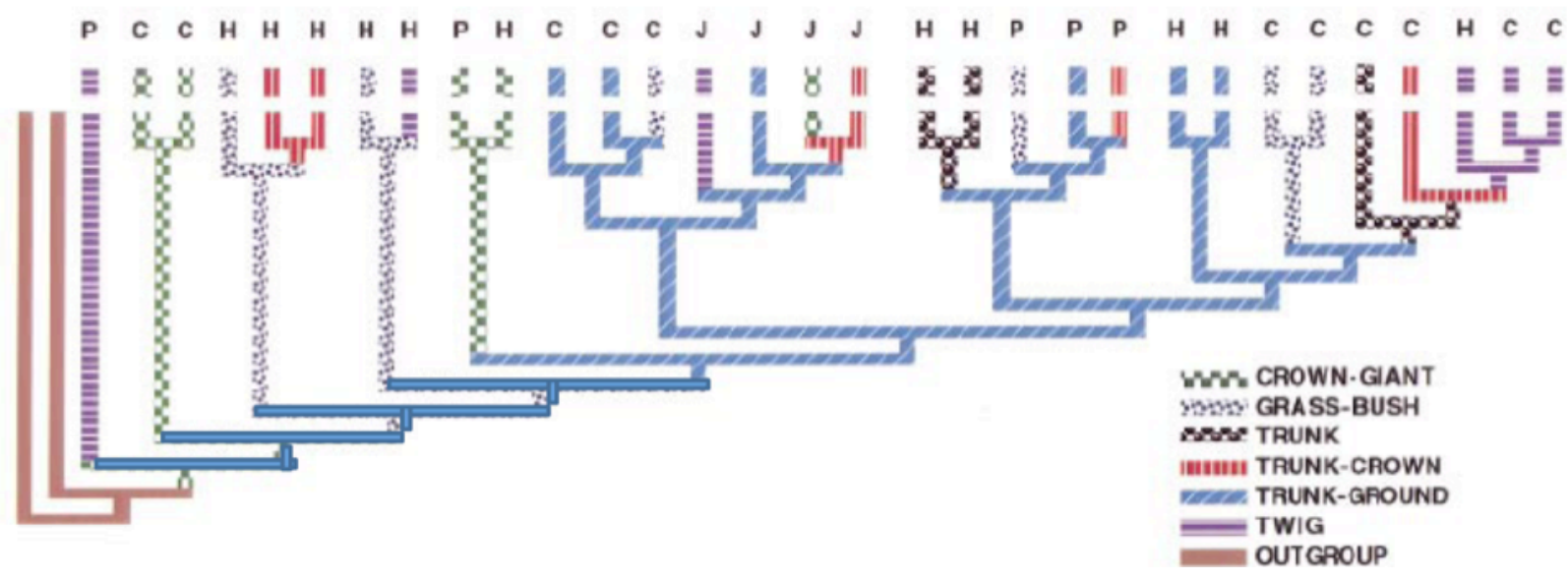


Figure 6. Example of reconstruction of ancestral state with high confidence (Schluter et al., 1997).

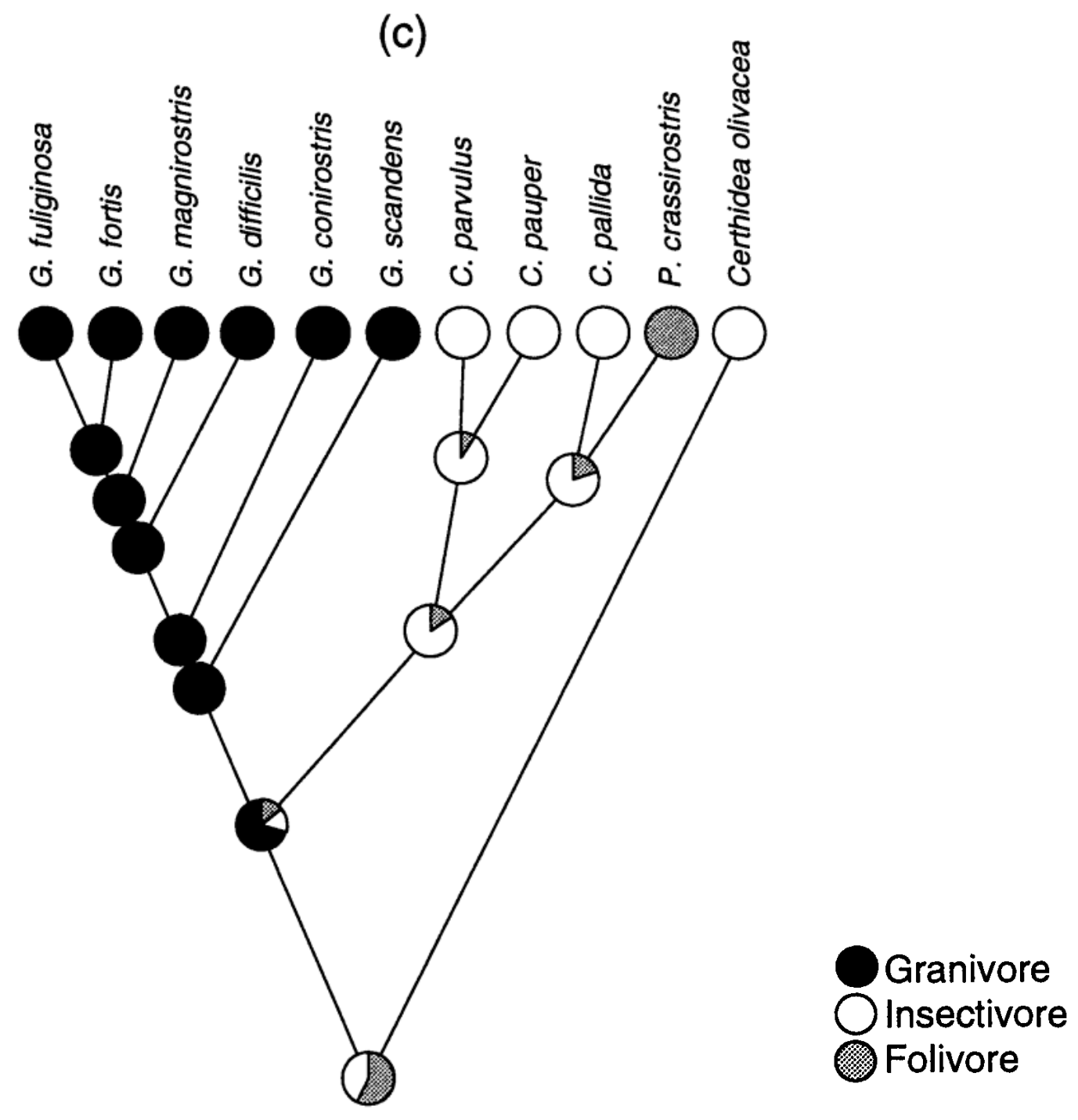


Figure 7. Part of the phylogeny of West Indian Anolis lizards. Many transitions have occurred between different habitat specialist character states. As a result, ancestral character states deep in the tree cannot be reconstructed with confidence. Rather, for most deep ancestral nodes, several different habitat specialist types are approximately equally likely, and none receives strong support (Losos, 2009).

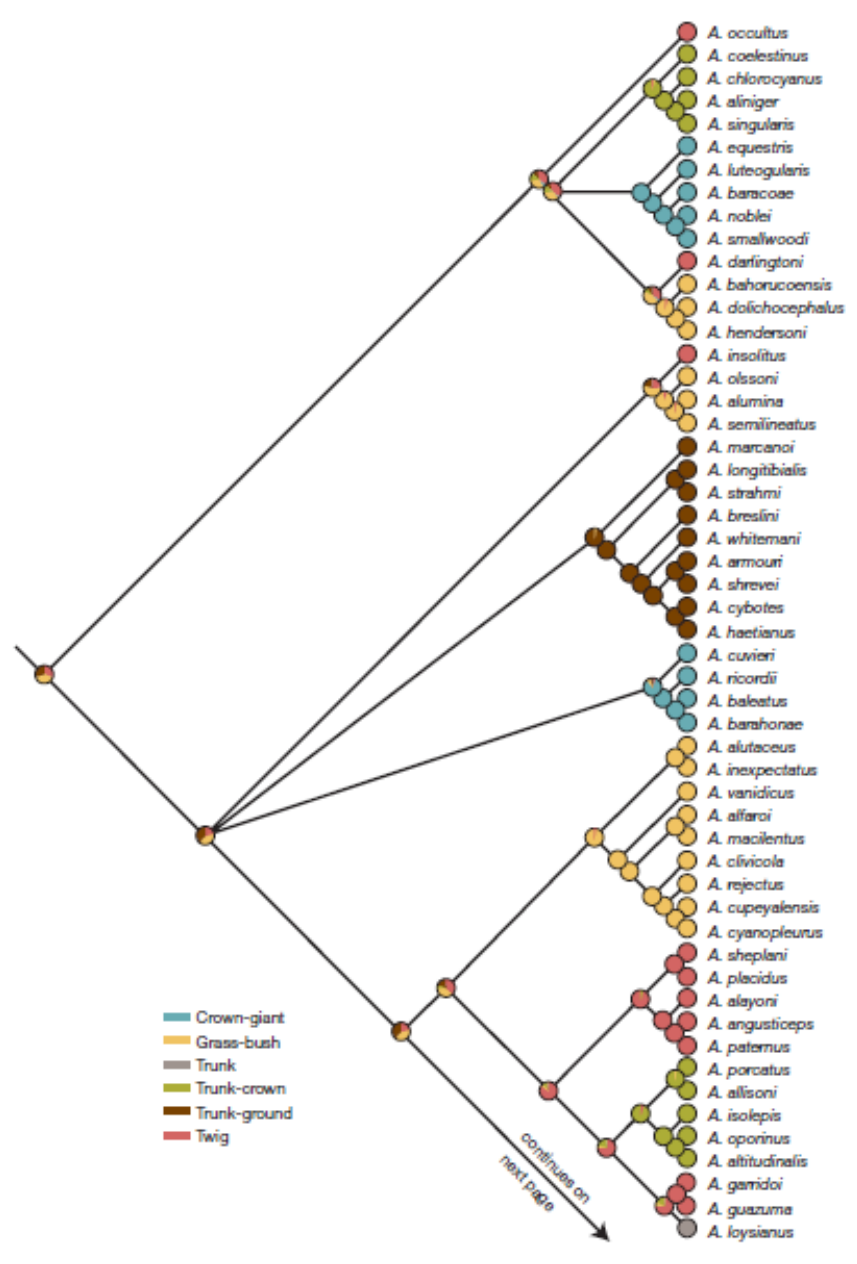


Figure 8. Ancestor character reconstruction fails when directional trends exist. (Oakley and Cunningham, 2000).

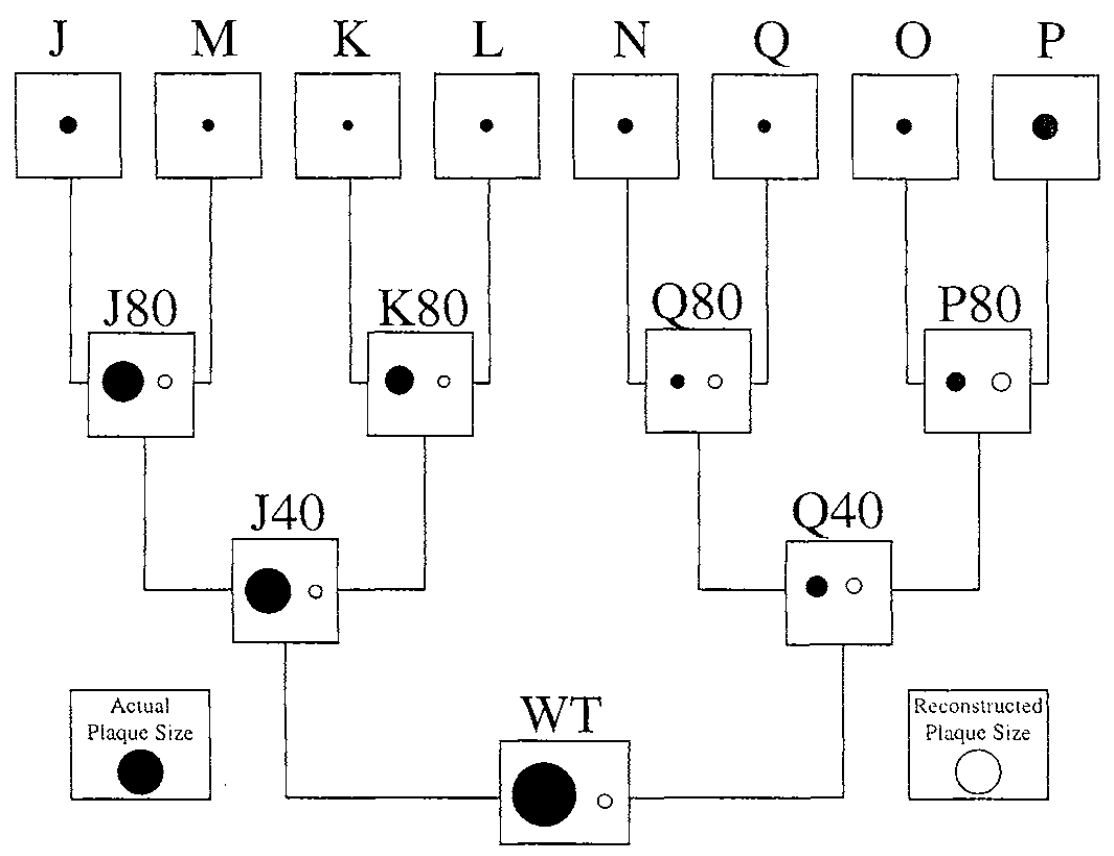


Figure 9. Comparison of ancestral size for fish families based on fossil data and on ancestor reconstruction using linear parsimony (Albert et al., 2009).

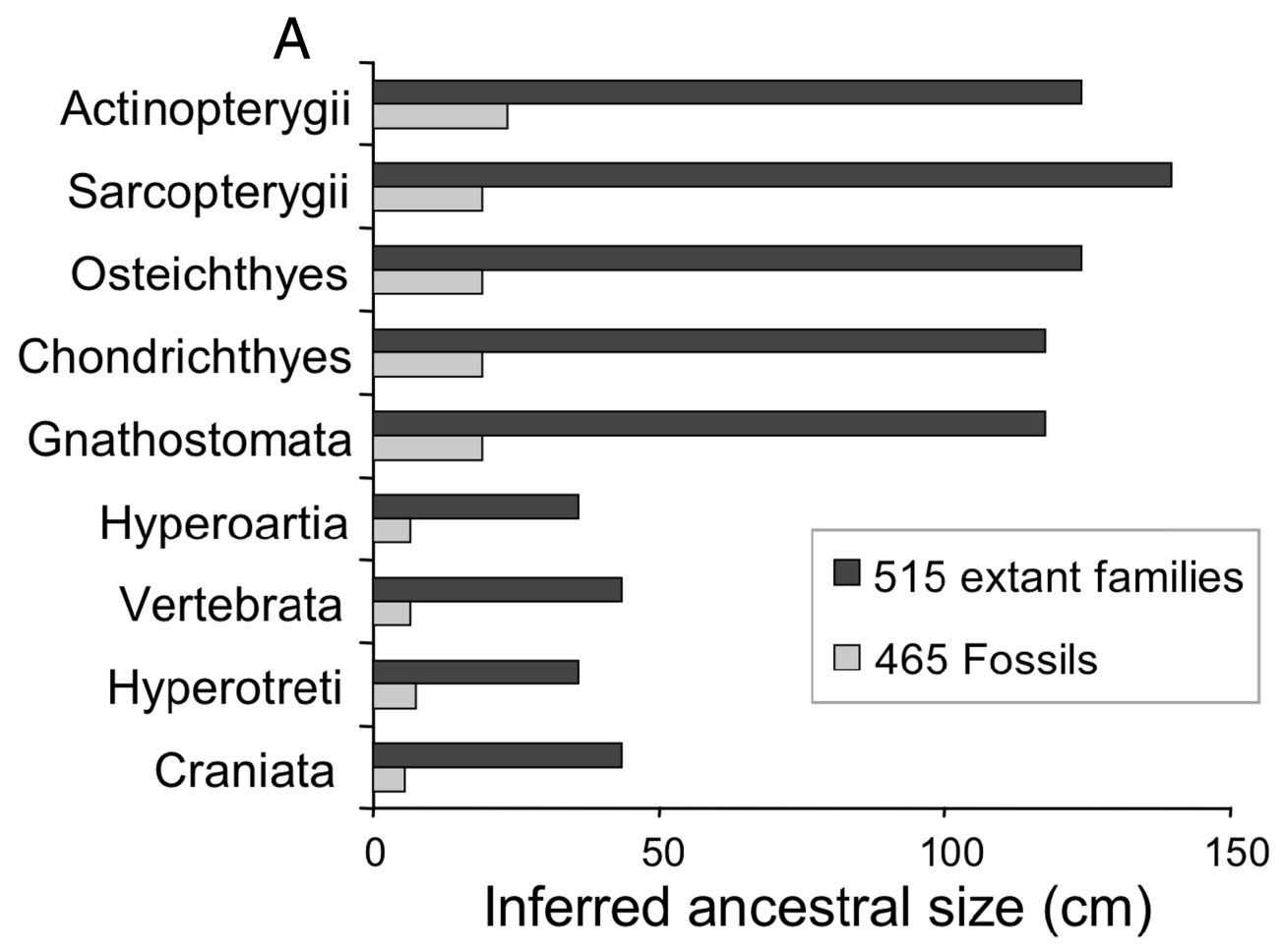


Figure 10. Change in range size of New Zealand mollusks through the course of each species' existence (Foote et al., 2007). Shaded figures are those in which the peak was short-lived and not at the endpoints of the species' stratigraphic range.

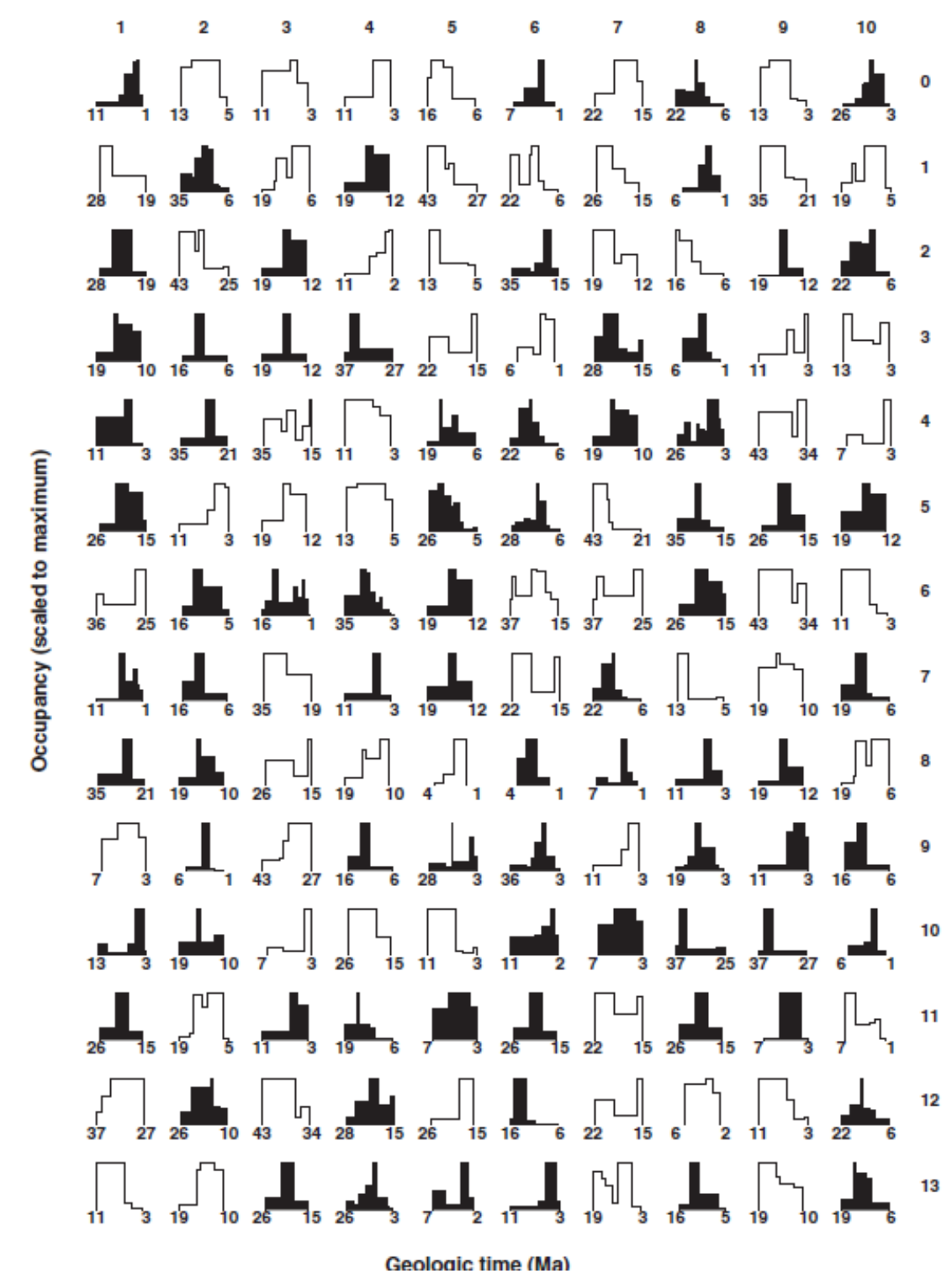

